\title{
WestVirginiaUniversity
}

THE RESEARCH REPOSITORY @ WVU

Graduate Theses, Dissertations, and Problem Reports

2011

\section{Effects of Delay Order and d-Amphetamine on Delay Discounting in Rats}

Shana R. Bailey

West Virginia University

Follow this and additional works at: https://researchrepository.wvu.edu/etd

\section{Recommended Citation}

Bailey, Shana R., "Effects of Delay Order and d-Amphetamine on Delay Discounting in Rats" (2011). Graduate Theses, Dissertations, and Problem Reports. 3341.

https://researchrepository.wvu.edu/etd/3341

This Thesis is protected by copyright and/or related rights. It has been brought to you by the The Research Repository @ WVU with permission from the rights-holder(s). You are free to use this Thesis in any way that is permitted by the copyright and related rights legislation that applies to your use. For other uses you must obtain permission from the rights-holder(s) directly, unless additional rights are indicated by a Creative Commons license in the record and/ or on the work itself. This Thesis has been accepted for inclusion in WVU Graduate Theses, Dissertations, and Problem Reports collection by an authorized administrator of The Research Repository @ WVU. For more information, please contact researchrepository@mail.wvu.edu. 
Effects of Delay Order and $d$-Amphetamine on Delay Discounting in Rats

Shana R. Bailey

\begin{abstract}
Thesis submitted to the Eberly College of Arts and Sciences at West Virginia University in partial fulfillment of the requirements for the degree of
\end{abstract}

\author{
Master of Science \\ in \\ Psychology
}

\author{
Karen G. Anderson, Ph.D., Chair \\ Michael Perone, Ph.D. \\ Constance Toffle, Ph.D. \\ Department of Psychology
}
Morgantown, West Virginia 2011

Keywords: Choice; $d$-Amphetamine; Delay Discounting; Impulsive Choice; Order of Delay; Rat 


\section{ABSTRACT \\ Effects of Delay Order and $d$-Amphetamine on Delay Discounting in Rats}

\section{Shana R. Bailey}

Impulsive choice is defined as choice for a smaller, more immediate reinforcer over a larger, more delayed reinforcer, whereas self-controlled choice is defined as choice for a larger, more delayed reinforcer over a smaller, more immediate reinforcer. Determinants of impulsive and self-controlled choices may be studied by employing delay-discounting procedures. When using a discrete-trials delay-discounting procedure, a difference in delay discounting as a function of order of presentation of delays to larger-reinforcer delivery was reported by one previous study, whereas another study reported no differences. In both studies, subjects had a history of exposure to both ascending and descending order of delay presentations prior to establishing stable delay-discounting functions with one or both order of delay presentations. Experiment 1 used a group design with Sprague-Dawley rats and a discrete-trials, within-session procedure to evaluate effects of order of delay presentation on delay discounting while controlling for history of exposure to different order of delay presentations. Levels of delay discounting (impulsive choice) were not systematically affected by order of delay presentation. Experiment 2 tested the impact of order of delay presentation on effects of $d$-amphetamine on delay discounting. Relative to saline, acute administration of the two largest doses of $d$-amphetamine tested resulted in decreases in mean area under the curve, regardless of order of delay presentation. 


\section{Acknowledgements}

I offer my thanks to WVU's Department of Psychology Student Research Fund for providing financial support for the expenses involved in completing this study. I would also like to thank Drs. Mike Perone and Connie Toffle for serving as members of my thesis committee. I would like to extend a special thanks to Dr. Karen Anderson for serving as my research advisor for the past two years and chair of my thesis committee. I greatly appreciate all of the guidance she has given me and the input she has provided throughout the course of this project. I would also like to extend thanks to all of the graduate students in the Anderson Lab, Sally Huskinson, Chris Krebs, and William Reilly, for help with data collection and other feedback provided during various discussions about the project. I extend thanks to all the undergraduate student workers in the lab who provided assistance with data collection. 
Table of Contents

\begin{tabular}{|c|c|}
\hline Abstract & ii \\
\hline Acknowledgements & _iii \\
\hline Table of Contents & iv \\
\hline List of Figures & $-\mathrm{V}$ \\
\hline List of Tables & -vi \\
\hline Introduction & -1 \\
\hline Delay Discounting & -1 \\
\hline Delay Discounting and Order of Delay Presentation & -5 \\
\hline Effects of $d$-Amphetamine on Delay Discounting & -6 \\
\hline Statement of the Problem & 10 \\
\hline Experiment 1 & 11 \\
\hline Method & 12 \\
\hline Subjects & 12 \\
\hline Apparatus & 12 \\
\hline Procedure & 13 \\
\hline Initial Training & 13 \\
\hline Delay-Discounting Procedure & 14 \\
\hline Data Analysis & 17 \\
\hline Results & 18 \\
\hline Discussion & 19 \\
\hline Experiment 2 & 22 \\
\hline Method & 22 \\
\hline Subjects & 22 \\
\hline Apparatus & 23 \\
\hline Procedure & 23 \\
\hline Equal-Delay Probe Sessions & 23 \\
\hline Delay-Discounting Procedure & 24 \\
\hline Acute Drug Administration & 24 \\
\hline Data Analysis & 25 \\
\hline Results & 26 \\
\hline Equal-Delay Probe Sessions & 26 \\
\hline Delay Discounting and $d$-Amphetamine & 27 \\
\hline Discussion & 29 \\
\hline General Discussion and Conclusions & 32 \\
\hline References & 34 \\
\hline
\end{tabular}




\section{List of Figures}

Figure 1. Mean percent larger-reinforcer choice for each rat and the Ascending and Descending Groups. All panels show mean percent larger-reinforcer choice on the y-axis and delay value on the $\mathrm{x}$-axis (larger values represent longer delays). For rats SB-1 through SB-7, delay values along the $\mathrm{x}$-axis were $0,10,20,40$, and $60 \mathrm{~s}$. For rat SB-8, delay values were $0,5,10,20$, and $40 \mathrm{~s}$. Mean percent larger-reinforcer choice for each rat in the Ascending Group is represented by filled circles in the first four left panels. Mean percent larger-reinforcer choice each rat in the Descending Group (DG) is represented by open circles in the four right panels. Bottom, Left Panel: Mean percent larger-reinforcer choice as a function of delay value is presented for the Ascending Group and Descending Groups. Mean percent larger-reinforcer choice is represented by filled symbols for rats in the Ascending Group and open symbols for rats in the Descending Group. All error bars represent \pm SEM

Figure 2. Top Panel: Mean area under the curve is shown by a black bar for rats in the Ascending Group and a cross-hatched bar for rats in the Descending Group. Bottom Panel: Mean indifference point (in s) is shown by a black bar for rats in the Ascending Group and a cross-hatched bar for rats in the Descending Group. All error bars represent +SEM

Figure 3. Mean percent-larger reinforce choice (y-axis) at saline (filled circles) and doses of $d$ amphetamine, including $0.1 \mathrm{mg} / \mathrm{kg}$ (open squares), $0.3 \mathrm{mg} / \mathrm{kg}$ (open diamonds), and $1.0 \mathrm{mg} / \mathrm{kg}$ (open triangles) is shown as a function of delay value (x-axis) for the Ascending (left panels) and Descending (right panels) Groups. All error bars represent \pm SEM

Figure 4. Top Panel: Mean area under the curve (y-axis) is presented as a function of dose of $d$ amphetamine in $\mathrm{mg} / \mathrm{kg}$ (x-axis) for Ascending (black bars) and Descending (cross-hatched bars) Groups. Asterisks indicate doses at which mean area under the curve was significantly lower, relative to saline, regardless of delay order. Bottom Panels: Mean percent of area under the curve at saline (y-axis) is presented as a function of dose of $d$-amphetamine in $\mathrm{mg} / \mathrm{kg}$ (x-axis) for the Ascending (left panel/black bars) and Descending (right panel/cross-hatched bars) Groups. The dashed line represents no change from area under the curve at saline. Error bars in all panels represent + SEM 


\section{List of Tables}

Table 1. Delay order, terminal delay value, sessions to stability, baseline area under the curve, and indifference points for individual rats

Table 2. Area under the curve during control sessions and with each dose of d-AMP (mg/kg) for each rat

Table 3. Appendix A. Mean percent larger-reinforcer choice across last 5 days of stable responding for each rat 46

Table 4. Appendix B. Mean percent larger-reinforcer choice at control, saline, and tested doses of d-amphetamine $(\mathrm{mg} / \mathrm{kg})$ for each rat in Experiment 2 


\section{Introduction}

Impulsivity has been correlated with a number of clinical disorders, including attentiondeficit/hyperactivity disorder (ADHD), substance abuse, and other impulse control disorders (American Psychiatric Association, 2000). Given these correlations, it is important to identify factors that influence impulsivity. Impulsivity may be operationally defined as a choice for a smaller, more immediate reinforcer over a larger, more delayed reinforcer. Self-control is the converse, that is, a choice for a larger, more delayed reinforcer over a smaller, more immediate reinforcer (cf. Ainslie, 1975; Logue, 1988; Mazur, 1987). These operational definitions allow for scientific investigation of impulsive behavior and potential for the discovery of factors that influence impulsive behavior.

\section{Delay Discounting}

One way to investigate both impulsive and self-controlled choice is to study delay discounting. Delay discounting occurs when there is a choice between a smaller, more immediate reinforcer and a larger, more delayed reinforcer, and the rate of choice for the larger reinforcer decreases as the delay to the larger reinforcer increases (cf. Mazur, 1987). More specifically, the larger reinforcer's efficacy, or ability to maintain responding, decreases as delay to its presentation increases. Choice for the larger, delayed reinforcer has been shown to decrease in a hyperbolic fashion as a function of an increasing delay to larger-reinforcer delivery (e.g., Mazur, 1987; Myerson \& Green, 1995). There are multiple procedures used to assess delay discounting, but each procedure arranges a choice between a smaller, more immediate reinforcer and a larger, more delayed reinforcer.

Increased levels of delay discounting have been correlated with a number of maladaptive behaviors, including drug abuse (Bickel, Odum, \& Madden, 1999; Coffey, Gudleski, Saladin, \& Brady, 2003; Odum, Madden, Badger, \& Bickel, 2000; Petry, 2001a), pathological gambling 
(Petry, 2001b), ADHD (Scheres, Tontsch, Thoeny, \& Kaczkurkin, 2010), and obesity (Weller, Cook III, Avsar, \& Cox, 2008). It is important to note that the correlations between delay discounting and these maladaptive behaviors do not establish causal relations. It is unknown whether greater levels of delay discounting underlie these maladaptive behaviors or if engaging in these maladaptive behaviors results in increased delay discounting. Additionally, individual learning history and biology could influence levels of delay discounting. However, given the positive correlations between increased delay discounting and the occurrence of these maladaptive behaviors, it is important to determine the factors that underlie delay discounting, as they may have implications for prevention and treatment of these problem behaviors.

Delay discounting has been observed in both humans (Weller, Cook III, Avsar, \& Cox, 2008; Coffey, Gudleski, Saladin, \& Brady, 2003; Petry, 2001b; Green, Fry, \& Myerson, 1994) and non-human subjects (Anderson \& Woolverton, 2003, 2005; Diller, Saunders, \& Anderson, 2008; Richards, Mitchell, de Wit, \& Seiden, 1997; Slezak \& Anderson 2009; Woolverton \& Anderson, 2006). Non-human subjects have been especially useful in investigating impulsive choice, because the use of non-human subjects allows for tighter control of the behavioral history of subjects than can be achieved through the use of human participants. One procedure that has been particularly useful for investigating factors that affect delay discounting is the fixed-ratio (FR) 1, discrete-trials, within-session procedure first employed by Evenden and Ryan (1996). This procedure arranges a choice between a smaller, immediate reinforcer and a larger, delayed reinforcer. Each session consists of five blocks of eight trials, with each trial lasting $100 \mathrm{~s}$. Delay to delivery of the larger reinforcer is always $0 \mathrm{~s}$ in the first block and increases across blocks within a session. Choice for the larger, delayed reinforcer is typically exclusive or near exclusive in the 0 -s block, but decreases across blocks as the delay to the presentation of the 
larger reinforcer increases, with choice being primarily for the smaller, immediate reinforcer in the last block of a session. By plotting percent larger-reinforcer choice in each block, area under the curve, the percentage of the graph's total area that falls under the plotted function, can be calculated (Myerson, Green, \& Warusawitharana, 2001). In addition, non-linear regression can be used to interpolate an indifference point, or the delay at which choice for the larger, reinforcer is $50 \%$, for each session. Both area under the curve and indifference points are used to quantify and compare delay-discounting functions. Larger area under the curve and longer indifference points indicate more self-controlled choice or less delay discounting.

In addition to the discrete-trials, within-session procedure, several other procedures used to study delay discounting also arrange a choice between a smaller, more immediate reinforcer and a larger, more delayed reinforcer. When using an FR 1, discrete-trials, between-session procedure, each session consists of several blocks of equal length trials, similar to the withinsession procedure described above. With the between-session procedure, however, delay to the delivery of the larger reinforcer remains the same across blocks within a given session, but varies across sessions. For example, during one session 36 choice trials might be arranged and in each trial the rat would choose between one immediate food pellet and three food pellets delivered after $10 \mathrm{~s}$. Then, during a session on the next day, the rat would again experience 36 choice trials, but during each trial the rat would choose between one immediate food pellet and three food pellets delivered after $20 \mathrm{~s}$. With this procedure, percent larger-reinforcer choice from multiple sessions (and therefore with multiple delays to larger-reinforcer delivery) can be used to determine area under the curve and indifference points.

When using an adjusting-delay procedure to examine delay discounting, delay to the presentation of the larger reinforcer is titrated based on the choice made in the previous trial. 
Choice for the smaller, immediate reinforcer results in a decrease in the delay to the presentation of the larger reinforcer. Conversely, choice for the larger, delayed reinforcer results in an increase in the delay to the presentation of the larger reinforcer. For example, if a trial arranged a choice between one immediate food pellet and three food pellets delivered after $10 \mathrm{~s}$ and three food pellets after $10 \mathrm{~s}$ was chosen, then the next trial would arrange a choice between one immediate food pellet and three food pellets delivered after $12 \mathrm{~s}$ (this delay is $2 \mathrm{~s}$ longer than in the previous choice trial). However, if the one immediate food pellet was chosen, rather than three food pellets after $10 \mathrm{~s}$, the next trial would arrange a choice between one immediate food pellet and three food pellets after $8 \mathrm{~s}$ (this delay is $2 \mathrm{~s}$ shorter than in the previous choice trial). A longer delay to presentation of the larger reinforcer at the end of a session indicates lower levels of delay discounting.

Another procedure used to study delay discounting is the adjusting-amount procedure, in which the amount of the smaller reinforcer is titrated based on choice in the previous trial. The smaller reinforcer is always presented immediately and the larger reinforcer is always presented after a set delay. Choice for the smaller, immediate reinforcer results in a decrease in the magnitude of the smaller reinforcer, whereas a choice for the larger, delayed reinforcer results in an increase. For example, if a trial arranged a choice between two immediate food pellets and six food pellets delivered after $10 \mathrm{~s}$ and six food pellets after $10 \mathrm{~s}$ was chosen, then the next trial would arrange a choice between three immediate food pellet and six food pellets after $10 \mathrm{~s}$. However, if two immediate food pellets was chosen, rather than six food pellets after $10 \mathrm{~s}$, then the next trial would arrange a choice between one immediate food pellet and six food pellets delivered after $10 \mathrm{~s}$. Indifference points are determined based on the amount of the smaller, immediate reinforcer. Larger indifference points represent less delay discounting. All of these 
procedures are effective for studying delay discounting, but a major benefit to using the discretetrial, within-session procedure described above, is that it allows for the assessment of choice for a range of set delays within a single session.

\section{Delay Discounting and Order of Delay Presentation}

When using discrete-trials procedures, the order in which delays to the larger reinforcer are presented have been reported to affect delay discounting. Fox, Hand, and Reilly (2008) generated delay-discounting functions using a discrete-trials, between-session procedure with rats. First, sessions were conducted in which there were no delays to the presentations of the smaller and larger reinforcers. These types of sessions occurred daily until choice for the larger reinforcer was almost exclusive. Then, delay-discounting functions were generated by increasing the delay to larger-reinforcer delivery in effect for each session across five sessions $(1,3,6,12,24 \mathrm{~s})$. Then, an additional session with a $24-\mathrm{s}$ delay to presentation of the larger reinforcer was conducted. Delay to presentation of the larger reinforcer was then decreased across the next five sessions $(12,6,3,1,0 \mathrm{~s})$. Fox et al. reported increased choice for the larger, delayed reinforcer, or lower levels of delay discounting at each delay, when delays were presented in an ascending order (increased across sessions) compared to when delays were presented in a descending order (decreased across sessions). However, contradictory results were reported by Slezak and Anderson (2009) when using a discrete-trials, within-session procedure, similar to the procedure first employed by Evenden and Ryan (1996). The order of the delay presentation (either ascending or descending) across blocks within a given session was selected at random each day by a coin toss, with the stipulation that neither order of presentation could be in effect for more than three consecutive sessions. Slezak and Anderson reported no differences in mean area under the curve based on order of delay presentation. These discrepant 
findings may be due to procedural differences in that Fox et al. used a between-session procedure and exposed rats to one order of delay presentation followed by exposure to another order of delay presentation, whereas Slezak and Anderson used a within-session procedure and randomly selected the order of delay presentation, either ascending or descending, at the start of each session.

In the Fox et al. (2008) study, prior to the presentation of delays in a descending order, all subjects had a history of ascending order of delay presentation. Additionally, in the Slezak and Anderson (2009) study, order of delay presentation (ascending or descending) was randomly selected prior to the start of each session resulting in all subjects having a history with both ascending and descending order of delay presentations prior to establishing stable responding with either order of delay presentation. Experiment 1 of the current study used a discrete-trials, within-session procedure and a group design to assess effects of order of delay presentation while controlling for history of exposure to different order of delay presentations. Half of the rats experienced delays presented in an ascending order (hereafter referred to as the Ascending Group), and half of the rats experienced delays in a descending order (hereafter referred to as the Descending Group).

\section{Effects of $d$-Amphetamine on Delay Discounting}

Studies investigating effects of $d$-amphetamine on delay discounting have reported discrepant findings. Some studies have found that $d$-amphetamine increases delay discounting (Charrier \& Thiebot, 1996; Evenden \& Ryan, 1996; Slezak \& Anderson, 2009). However, other studies have shown that $d$-amphetamine decreases delay discounting (de Wit, Enggasser, \& Richards, 2002; Wade, de Wit, \& Richards, 2000; Winstanley, Dallery, Theobald, \& Robbins, 2003). In addition, several studies have reported varying $d$-amphetamine effects within a single 
study, with $d$-amphetamine resulting in decreases in delay discounting in some instances, but increases or no effect in others (Cardinal, Robbins, \& Everitt, 2000; Hand, Fox, \& Reilly, 2009; Perry, Stairs, \& Bardo, 2008). Differences in effects of $d$-amphetamine reported in the studies discussed here are not attributable to route of drug administration, as all studies using rats administered $d$-amphetamine via interperitoneal (ip) injection. The differences in effects of $d$ amphetamine may be due to differences in baseline rates of delay discounting and procedural variables, such as the delay-discounting procedure used or use of signals during the delay to the larger reinforcer.

Recent findings suggest that baseline differences in delay discounting may result in different effects of $d$-amphetamine on delay discounting. Perry et al. (2008) reported that different rearing conditions resulted in different degrees of baseline delay discounting in two groups of rats. Rats in one group were reared in isolation with no novel objects in the home cages (hereafter referred to as the IC group) and the other group of rats was reared in an enriched environment with novel toys and social cohorts in the home cage (hereafter referred to as the EC group). Both groups of rats were trained using an adjusting-delay procedure. The IC group showed significantly greater levels of delay discounting (less self-controlled choice), measured as a lower mean adjusted delay, than the EC group at baseline. However, when $d$-amphetamine was administered acutely, the $2.0 \mathrm{mg} / \mathrm{kg}$ dose resulted in the mean adjusted delay for the IC group being significantly longer than the mean adjusted delay for the EC group. Furthermore, the IC group's mean adjusted delay following $d$-amphetamine administration was significantly longer than the baseline mean adjusted delay for the group. The EC group, on the other hand, showed a significantly lower mean adjusted delay with administration of the $2.0 \mathrm{mg} / \mathrm{kg}$ dose of $d$-amphetamine compared to baseline. Overall, $d$-amphetamine increased delay discounting 
(decreased self-controlled choice) when baseline levels delay discounting were low, but decreased delay discounting (increased self-controlled choice) when baseline levels of delay discounting were high.

Hand et al. (2009) used a discrete-trials, between-session procedure and group design (one group of Wistar-Kyoto (WKY) rats and one group of spontaneously hypertensive rats (SHR)), and found less delay discounting (more self-controlled choice), at baseline, in the WKY group compared to SHR group. When $d$-amphetamine was administered acutely, 1.0 and 3.2 $\mathrm{mg} / \mathrm{kg}$ doses increased delay discounting (decreased self-controlled choice) in the WKY group at all delays, but did not affect delay discounting in the SHR group. It is impossible to determine if the different effects of $d$-amphetamine on delay discounting reported by Hand et al. were due to baseline differences in delay discounting or strain difference between the WKY and SHR rats. Both Hand et al. and Perry et al. (2008) reported that when baseline levels of delay discounting were low, acute $d$-amphetamine increased delay discounting (decreased self-controlled choice). The findings of the two studies, however, vary in that Perry et al. reported a decrease in levels of delay discounting (increase in self-controlled choice) following administration of $d$-amphetamine when baseline levels of delay discounting were high, whereas Hand et al. reported no effect of $d$ amphetamine on delay discounting when baseline levels of delay discounting were high. Despite the discrepancies in the findings of Perry et al. and Hand et al., both studies may provide evidence for a role of baseline levels of delay discounting in determining effects of $d$ amphetamine on delay discounting.

Wade et al. (2000) used an adjusting-amount procedure with rats and reported that $d$ amphetamine resulted in increases in indifference points, which represents a decrease in delay discounting (increase in self-controlled choice). However, Evenden and Ryan (1996) used a 
discrete-trials, within-session procedure with rats and reported decreased larger-reinforcer choice, indicating an increase in delay discounting (decrease in self-controlled choice), following acute $d$-amphetamine administration. Therefore, the type of procedure used to investigate delay discounting may have an impact on effects of $d$-amphetamine.

While observing no differences in baseline delay discounting as a function of signalled versus unsignalled delays to the larger reinforcer, Cardinal et al. (2000) reported different effects of $d$-amphetamine. Cardinal et al. used a discrete-trials, within-session procedure with rats. When delay to the presentation of the larger reinforcer was signalled, $d$-amphetamine increased percent larger-reinforcer choice (decreased delay discounting/increased self-controlled choice), but when the delay was unsignalled, $d$-amphetamine resulted in a decrease in percent largerreinforcer choice (increased delay discounting/decreased self-controlled choice). Contradictorily, Slezak and Anderson (2009) reported that, regardless of signal condition, acute administration of larger doses of $d$-amphetamine resulted in decreases in choice for the larger, more delayed reinforcer (increased delay discounting/decreased self-controlled choice). Thus, the procedural variable of signals during the delay to the larger reinforcer may impact effects of $d$ amphetamine.

Though no differences in effects of $d$-amphetamine as a function of signal during the delay were reported by Slezak and Anderson (2009), $d$-amphetamine effects did differ as a function of order of delay presentation. As stated above, Slezak and Anderson reported no differences in baseline delay discounting as a function of ascending versus descending order of delay presentation, but did report a delay order by dose interaction with acute $d$-amphetamine administration. Larger doses of $d$-amphetamine resulted in significantly lower area under the curve values, relative to area under the curve values with saline, with both ascending and 
descending delay presentation. Decreases in area under the curve, however, were significantly greater with descending relative to ascending delay presentation. Thus, order of delay presentation is another procedural variable that may be important in determining effects of $d$ amphetamine on delay discounting.

\section{Statement of the Problem}

In one study investigating effects of order of delay presentation on baseline delay discounting, exposure to an ascending order of delay presentation preceded exposure to a descending order of delay presentation (Fox et al. 2008). In another study, exposures to both ascending and descending order of delay presentations preceded stable responding with either order of delay presentation (Slezak \& Anderson, 2009). Fox et al. reported differences in delay discounting as a function of order or delay presentation, but Slezak and Anderson reported no effect of delay order on delay discounting. Given the procedures used in the two studies mentioned above, it is unclear if delay discounting varies as a function of order of delay presentation, when there is no history of exposure to multiple orders of delay presentations prior to establishing stable delay discounting. Therefore, Experiment 1 was designed to determine effects of order of delay presentation on delay discounting when delay discounting was established with one order of delay presentation before exposure to any alternative orders of delay presentation. Experiment 1 of the present study used a group design to control for exposure to different orders of delay presentation prior to establishing baseline delay-discounting functions. Half of the rats were exposed to an ascending order of delay presentation (Ascending Group) and the other half of the rats were exposed to a descending order of delay presentation (Descending Group). Experiment 1 used an FR 1, discrete-trials, within-session procedure to determine effects of order of delay presentation on delay discounting. 
Slezak and Anderson (2009) reported that, when baseline levels of delay discounting were comparable with both ascending and descending orders of delay presentation, the degree of decreases in area under the curve with acute administration of $d$-amphetamine differed with ascending and descending orders of delay presentation. The impact of order of delay presentation on effects of $d$-amphetamine is not a well-established finding within delaydiscounting literature. Experiment 2 of the present study, therefore, is a systematic replication of Slezak and Anderson's investigation of impact of order of delay presentation on effects of acute $d$-amphetamine administration on delay discounting. Slezak and Anderson used a discrete-trials, within-session delay-discounting procedure and at the beginning of each session, for each rat, randomly determined the order of delay presentation (ascending or descending) in effect for that session. Experiment 2 of the present study used a discrete-trials, within session procedure similar to the procedure used by Slezak and Anderson, but used a group design in which rats were exposed to only one order of delay presentation (ascending or descending) for the duration of the experiment in order to further investigate the generality of the findings reported by Slezak and Anderson.

\section{Experiment 1}

Fox et al. (2008) reported effects of order of delay presentation on delay discounting. Descending order of delay presentation resulted in increased levels of delay discounting (decreased self-controlled choice), relative to ascending order of delay presentation. However, contradictory results were reported by Slezak and Anderson (2009) who found no differences in baseline delay discounting as a function of ascending or descending order of delay presentation. In Fox et al., exposure to an ascending order of delay presentation preceded exposure to a descending order of delay presentation for all rats, and, in Slezak and Anderson, order of delay 
presentation was selected randomly before the start of each session, therefore, exposure to both ascending and descending order of delay presentations preceded stable responding with either order of delay presentation. Experiment 1 used a group design to control for exposure to different order of delay presentations prior to establishing baseline delay-discounting functions. An FR 1, discrete-trials, within-session procedure was used, and rats were divided into two groups (Ascending and Descending).

\section{Method}

Subjects. Eight experimentally naive, male Sprague-Dawley rats served as subjects. Rats were housed individually in a colony room at West Virginia University (WVU). Body weights were maintained (or increased) over the course of the study to allow for normal growth and development. Rats were food restricted for approximately $22 \mathrm{hr}$ prior to each experimental session and were given ad libitum access to water in the home cage. The rat colony room was maintained at approximately $21-27^{\circ} \mathrm{C}$. A 12 -hr reverse light/dark cycle was utilized. All housing and experimental procedures were approved by the WVU Animal Care and Use Committee.

Apparatus. Experimental sessions were conducted in eight operant-conditioning chambers for rats, each enclosed in a melamine sound-attenuating cubicle (Med Associates, VT). Each chamber contained a working area of $30.5 \mathrm{~cm}$ by $24.1 \mathrm{~cm}$ by $21.0 \mathrm{~cm}$, a grid floor, and a 45-mg pellet dispenser with a pellet receptacle centered between two standard retractable response levers, which were $11.5 \mathrm{~cm}$ apart from each other, required at least $0.25 \mathrm{~N}$ for a response to be recorded, were $4.8 \mathrm{~cm}$ wide, protruded $1.9 \mathrm{~cm}$ into the chamber, and were elevated $8 \mathrm{~cm}$ from the grid floor. Two $28-\mathrm{V}$ stimulus lights of $2.5 \mathrm{~cm}$ in diameter were approximately $7 \mathrm{~cm}$ above each lever. Each chamber had a $28-\mathrm{V}$ houselight on the wall opposite 
the wall containing operandum, and a ventilation fan to circulate air and to mask extraneous noise. Equipment was interfaced to a computer and routines were programmed and conducted with MedPC-IV (Med Associates, VT).

Procedure. Procedures included feeder training, lever-press training, and a delaydiscounting task. Sessions were conducted seven days per week.

Initial training. The initial session was feeder training and the procedure was similar to that used by Slezak and Anderson (2009). During this session, food pellets were delivered according to a variable-time (VT) 60-s schedule. The houselight was illuminated at the start of the session and remained illuminated throughout. Each food pellet delivery was paired with a 0.1-s flash of the houselight. The flash of the houselight with each food-pellet delivery occurred during all sessions throughout the study. Levers were retracted for the duration of the session, which terminated after 60 food pellets were delivered.

Following feeder training, lever-press training occurred. In the initial lever-press training session, food pellets were delivered following responses on the operative lever according to a tandem FR 1, differential-reinforcement-of-other-behavior (DRO) 20-s schedule. With the resetting DRO, responses on the inoperative lever (whichever was not the operative lever for each rat) were counted and reset the DRO timer, but had no other programmed consequences. Ultimately, one food pellet was delivered when, following a response on the operative lever, $20 \mathrm{~s}$ elapsed with no responses on either lever. The right lever was the operative lever for two rats in the Ascending Group and two rats in the Descending Group, and the left lever was operative for two rats in each group. At the start of the session, both levers were extended into the chamber and the houselight and light above each lever were illuminated. The levers remained extended 
and the houselight and lever lights remained illuminated for the duration of the session. The session was terminated after eight hours, regardless of the number of pellets earned.

Next, food pellets were presented following each response on either the right or left lever as well as every $60 \mathrm{~s}$ independent of responding (conjoint FR 1 VT 60-s schedule). At the start of the session, the houselight was illuminated, the left and right levers were extended into the chamber, and the lights above the left and right levers were illuminated. Both the houselight and the lights above the levers remained illuminated and the levers were extended into the chamber for the duration of the session. The session terminated after 40 food pellets were delivered. Daily sessions using this procedure were conducted until at least 35 food pellets were earned by lever pressing.

During the last phase of training, to ensure responding on both levers, food was delivered according to an FR 1 schedule, alternating between levers after every fifth lever press. At the start of the session, the houselight was illuminated, the left lever was extended into the chamber, and the light above the left lever was illuminated. A food pellet was delivered following each left lever press. After delivery of the fifth food pellet, the left lever retracted and the light above the left lever extinguished. The right lever extended into the chamber and the light above the right lever illuminated. Food pellets were delivered according to an FR 1 schedule, so each press on the right lever resulted in delivery of a food pellet. The lever associated with the FR 1 schedule in effect alternated after five food pellets were delivered until a total of 40 food pellets were delivered.

Delay-Discounting Procedure. Following lever-press training, an FR 1, discrete-trials choice procedure was in effect. The procedure was similar to the procedure developed by Evenden and Ryan (1996). At the onset of the session, there was a programmed 10-min blackout 
period, during which the chamber was dark and the levers were retracted. Following the blackout, each session consisted of five blocks of eight trials, two forced-choice trials followed by six free-choice trials. Trials started every $100 \mathrm{~s}$, thus intertrial intervals (ITI) were variable. Forced-choice trials provided exposure to the outcome associated with pressing each lever. During the first forced-choice trial, either the right or left lever (randomly selected) was extended into the chamber and the light above that lever was illuminated. One press of the extended lever resulted in the lever being retracted and the light above the lever being extinguished. If the lever was associated with the delivery of one food pellet then a single pellet was delivered immediately following the lever press. If the extended lever was associated with the delayed delivery of three food pellets, following the lever press, the houselight remained illuminated for the duration of the delay in effect for that block of trials. Then, after the delay elapsed, three food pellets were delivered. Following food-pellet delivery, the houselight extinguished and the chamber remained dark for the duration of the 100 -s trial. The second forced-choice trial followed the same procedure using the lever that was not extended in the first forced-choice trial. The lever associated with the smaller outcome (one food pellet) and the lever associated with larger outcome (three food pellets) was held constant for each rat for the duration of the study, but was counterbalanced across rats within each group.

Following forced-choice trials, the remaining six trials in each block were free-choice trials, where choice was arranged between the smaller (one food pellet) and larger (three food pellets) outcomes. At the beginning of each trial, both the left and right levers extended into the chamber and the houselight and light above each lever were illuminated. One press on either lever resulted in the same consequence that occurred with one press of that lever during the forced-choice trials in that block. If in any trial (forced or free), there was no lever press within 
$30 \mathrm{~s}$ of the onset of the trial, the lever(s) retracted and the light(s) above the lever(s) and the houselight extinguished. The chamber was dark for the remainder of the trial (a 70-s ITI) and an omission was recorded.

Rats in the Ascending Group ( $n=4)$, were exposed to an ascending order of delay presentation. The delay to the presentation of the larger outcome (three food pellets) was always $0 \mathrm{~s}$ in the first block of trials and increased across blocks within a session. Rats in the Descending Group $(n=4)$ were exposed to descending delay sequences presented across block of trials within a session. There was always a 0-s delay for both alternatives in the last block of each session. During initial sessions using the delay-discounting procedure, the delay sequence for the Ascending Group was 0, 1, 2, 4, 8 s across blocks. For the Descending Group, the delay sequence was 8, 4, 2, 1, 0 s across blocks. As in Slezak and Anderson (2009), delay values across blocks within a session were increased if choice maintained by the larger outcome during free-choice trials was $50 \%$ or greater in each block for two consecutive days. Increases were to 0, 2, 4, 8, $16 \mathrm{~s}$ for the Ascending Group and 16, 8, 4, 2, $0 \mathrm{~s}$ for the Descending Group, then to 0, $5,10,20,40 \mathrm{~s}$ or $40,20,10,5,0 \mathrm{~s}$, and then to $0,10,20,4060 \mathrm{~s}$ or $60,40,20,10,0 \mathrm{~s}$. Terminal delay sequences were individually determined for each rat. Functionally determining terminal delay sequences for each rat avoided floor and ceiling effects of baseline delaydiscounting functions.

Sessions were conducted daily for a minimum of 30 sessions and until stability criteria were met. Stability criteria included at least $80 \%$ (5 out of 6 ) choice for the larger outcome (three food pellets) in the 0-s delay block and no increasing or decreasing trends in delaydiscounting functions, assessed through visual inspection of the data, across the last five sessions. In addition, total number of larger-outcome choices per session could not vary by more 
than $20 \%$ across the last five sessions. Due to 50 or $67 \%$ larger-reinforcer choice in the 0 -s delay block every four or five sessions, the criteria for stable responding for rat SB-7 were amended to require a mean of at least $80 \%$ larger-reinforcer choice in the 0 -s delay block across the last five sessions, rather than at least $80 \%$ larger-reinforcer choice in the 0 -s delay block during each of the last five sessions.

Data Analysis. The primary dependent variable was mean percent larger-reinforcer choice as a function of delay to larger-reinforcer delivery. Delay-discounting functions were generated using mean percent larger-reinforcer choice at each delay value. Means are comprised of percent larger-reinforcer choice during free-choice trials during the last five stable sessions. A 2 x 5 (Delay Order [ascending, descending] x Delay Value (larger numbers indicate longer delays) [one, two, three, four, five]) mixed analysis of variance (ANOVA) was conducted to analyze the dependent measure of percent larger-reinforcer choice. In addition, mean sessions to stability were examined for differences as a function of order of delay presentation (ascending versus descending) using an independent means t-test.

Furthermore, mean percent larger-reinforcer choice during free-choice trials in the last five stable sessions was used to calculate area under the curve for each individual rat's, delaydiscounting function as a way to quantify and compare delay discounting. Area under the curve was calculated using methods described by Myerson et al. (2001). To calculate area under the curve, delay-discounting functions were generated by graphing mean percent larger-reinforcer choice on the y-axis and delay to larger-reinforcer delivery on the x-axis. Delay values were normalized so the lowest delay value on the $\mathrm{x}$-axis was 0.0 and the longest delay value was 1.0 . Mean percent larger-reinforcer choice in each block was plotted and points were connected to create a delay-discounting function. Vertical lines were then drawn from each point on the graph 
down to the $\mathrm{x}$-axis, to create four trapezoids under the delay-discounting curve. The area of each trapezoid was calculated and the sum of the area of the four trapezoids was divided by the total area of the graph, which was 1.0. Area under the curve values range from 0.0 to 1.0. The closer the area under the curve is to 1.0, the lower the level of delay discounting. In addition to area under the curve, indifference points were interpolated. A line of best fit to mean percent largerreinforcer choice in each block across a session was generated using non-linear regression. Indifference points were interpolated from the line of best fit. Independent means t-tests were used to examine area under the curve and indifference points for differences as a function of order of delay presentation (ascending versus descending).

\section{Results}

Stable delay-discounting functions were obtained for all rats and there were few or no omissions recorded for each rat. Figure 1 shows mean percent larger-reinforcer choice as a function of delay to larger-reinforcer delivery for each rat in the Ascending (top four left panels) and Descending (right panels) Groups. See Appendix A for percent larger-reinforcer choice from the five sessions used to generate the delay-discounting function for each rat. Mean percent larger-reinforcer choice for both groups is also presented in Figure 1 (bottom, left panel). For all rats, as duration of the delay to larger-reinforcer delivery increased, choice for the largerreinforcer decreased. To supplement the visual inspection of the data, a 2 (delay order) x 5 (delay value) mixed ANOVA was used to analyze mean percent larger-reinforce choice. The ANOVA showed a significant main effect of delay value, $\mathrm{F}(4,24)=47.50, p<.001$, on percent largerreinforcer choice .

Area under the curve and indifference points for each rat are presented in Table 1. Mean area under the curve (Ascending mean $=0.52, \pm 0.09$; Descending mean $=0.52, \pm 0.04$ ) was 
identical for both groups. Thus, there was not a statistically significant difference in mean area under the curve across Ascending and Descending Groups (see top panel of Figure 2). Mean indifference points (Ascending mean $=31.36 \mathrm{~s}, \pm 8.82$; Descending mean $=30.78 \mathrm{~s}, \pm 6.29$ ) were similar in both groups (see bottom panel of Figure 2). An independent means t-test revealed no significant difference in mean indifference points, $\mathrm{t}(6)=0.05, \mathrm{p}=.96$, across the Ascending and Descending Groups.

Table 1 shows the number of sessions required to meet stability criteria for each rat. The mean number of sessions to stability was greater for the Descending Group (mean $=77.25, \pm$ 26.37) compared to the Ascending Group ( mean $=49.00, \pm 7.38$ ). An independent means t-test revealed no statistically significant difference between mean sessions to stability in the Ascending and Descending Groups, $t(6)=-1.03, p=.34$. The number of sessions to stable delay discounting, however, was more variable with a descending (ranging from 36 to 148 sessions), relative to ascending (ranging from 30 to 66 sessions), order of delay presentation.

\section{Discussion}

Delay discounting was observed in all rats. Generally, as the delay to delivery of the larger reinforcer increased, choice for the larger reinforcer decreased. This pattern of responding in the context of discrete-trials, delay-discounting procedures is consistent with patterns of responding reported in earlier studies (e.g. Anderson \& Diller, 2010; Evenden \& Ryan, 1996; Madden, Smith, Brewer, Pinkston, \& Johnson, 2008; Slezak \& Anderson, 2011).

Replicating results reported by Slezak and Anderson (2009), delay discounting, as characterized by percent larger-reinforcer choice and area under the curve, was similar with both ascending and descending order of delay presentations. This finding, however, is inconsistent with Fox et al.'s (2008) report of greater levels of delay discounting (fewer self-controlled 
choices) with a descending, relative to ascending, order of delay presentation. Several procedural differences between the Fox et al. study and the Slezak and Anderson and present studies might account for the discrepant results. First, Fox et al. used a between-session procedure where delays to larger-reinforcer delivery were the same in all blocks within a session and changed across sessions, whereas Slezak and Anderson and the present study employed a within-session procedure in which delays were changed across blocks within a session. Order of delay presentation may affect delay discounting in the context of a between-session procedure, but have no effect in the context of a within-session procedure. A between-session procedure provides repeated exposure to each delay value (all blocks of trials in a session) prior to exposure to a different delay value. A within-session procedure, however, provides limited exposure to each delay value (one block of trials in a session) prior to exposure to a different delay value. More exposure to a given delay value may result in greater carry-over effects when a new delay value is presented, resulting in different delay-discounting functions with ascending versus descending order of delay presentation with between-session, but not within-session, procedures.

The different delay-discounting procedures used by Fox et al. (2008) and Slezak and Anderson (2009) and the present study also result in different overall contexts within a session. With a between-session procedure, the overall context within a session is one of consistency (regardless of order of delay presentation in effect), as delay to larger-reinforcer delivery is held constant within a session. With a within-session procedure, however, the overall context in a single session is one of change and differs as a function of order of delay presentation. When an ascending order of delay presentation is in effect, the overall context within a session can be described as getting "worse," as delay durations increase as the session progresses. With a descending order of delay presentation, the overall context within a session can be described as 
getting "better," as delay durations decrease as the session progresses. Thus, the overall withinsession context may be a factor in determining the impact of order of delay presentation on delay discounting.

Second, in Fox, et al. (2008), each delay value (1, 3, 6, 12, and $24 \mathrm{~s})$ was experienced by each rat in one session in the ascending condition and in one session in the descending condition. Each delay value was first in effect when delays were presented in an ascending order (delay value increased in each subsequent session) and then when delays were presented in a descending order (delay value decreased in each subsequent session) immediately following ascending order of delay presentation. In the Slezak and Anderson (2009) study, rats were exposed to ascending and descending orders of delay presentation (with order selected at random prior to each session) across numerous sessions until stable responding with both orders of delay presentation was established. In the present study, rats were exposed to only one order of delay presentation (half ascending and half descending) in multiple sessions until stable responding was established. It is possible that the differences in delay discounting as a function of delay order reported by Fox et al. can be attributed to limited exposure to each delay value. Repeated exposure to each delay value might have generated steady-state responding that was more similar to the results reported by Slezak and Anderson and the present study.

Additionally, in the Fox et al. (2008) study, all rats were exposed to delay values in an ascending order prior to exposure in a descending order. The present study controlled for history of exposure to different order of delay presentations and the Slezak and Anderson (2009) study insured exposure to both order of delay presentations multiple times, and at random, and neither study found an effect of order of delay presentation on delay discounting. It is possible that the findings reported by Fox et al. were a function of failing to counterbalance the sequence in which 
rats were exposed to different orders of delay presentation. Additional research would be required to determine if the same differences in delay discounting as a function of order of delay presentation would be observed if rats were exposed to a descending order of delay presentation prior to exposure to an ascending order of delay presentation with the procedure employed by Fox et al. Additional research is needed to further determine what behavioral histories and experimental contingencies will result in differences in delay discounting as a function of order of delay presentation.

\section{Experiment 2}

Slezak and Anderson (2009) found no differences in baseline delay discounting as a function of order of delay presentation. The authors did, however, report that acute administration of $d$-amphetamine resulted in significantly greater increases in delay discounting (decrease in self-controlled choice) when a descending order of delay presentation was in effect compared to an ascending order of delay presentation. Experiment 2 was a systematic replication of Slezak and Anderson's investigation of the role of order of delay presentation in determining effects of $d$-amphetamine on delay discounting. Experiment 2 examined the generality of the impact of order of delay presentation on effects of $d$-amphetamine on delay discounting, when no differences in baseline delay discounting were reported. The subjects, apparatus, and delaydiscounting procedure from Experiment 1 were used in Experiment 2.

\section{Method}

Subjects. The eight male Sprague-Dawley rats that served as subjects in Experiment 1 also served as subjects in Experiment 2. Housing conditions remained the same for the duration of both Experiments 1 and 2 . 
Apparatus. The eight rat operant-conditioning chambers used were the same chambers used in Experiment 1.

Procedure. Procedures included equal-delay probe sessions, a delay-discounting task, and acute administration of $d$-amphetamine. Sessions were conducted seven days per week.

Equal-Delay Probe Sessions. After stable delay discounting was established (Experiment 1) and prior to $d$-amphetamine administration, equal-delay probe sessions were conducted to demonstrate sensitivity to the differences in magnitude of the larger and smaller outcomes. Across all blocks, for each rat, the delay to the delivery of both the smaller and larger outcome was equal to the programmed delay to the delivery of three food pellets during the first block of the delay sequence in effect during Experiment 1. For the Ascending Group, the delay to both the smaller and larger outcome was $0 \mathrm{~s}$. For the Descending Group, the delay to both the smaller and larger outcome was the same as the terminal (longest) delay value for each rat, $(60 \mathrm{~s}$ for all rats with the exception of SB-8 at $40 \mathrm{~s}$ ). The stability criterion for probe sessions was at least $80 \%$ (5 out of 6 ) larger-outcome choice (three food pellets) in four out of five blocks and at least $67 \%$ (4 out of 6) larger-outcome choice in one block.

Probe sessions were conducted on consecutive days, if necessary, and until the stability criterion was met or for a maximum of 20 sessions. If responding during initial probe sessions met the stability criterion after one or two sessions, subsequent sessions used the delay-procedure described in Experiment 1. If the criterion for stable responding during probe sessions was not met within two sessions, additional probe sessions were conducted weekly (starting on Wednesdays), until the criterion for stable responding during probe sessions was met within two sessions. To avoid potential lever biases and minimize possible carry-over effects from the previous week's probe sessions, probe sessions were omitted in a given week if a minimum of 
five days had not passed since the most recent probe session and mean percent larger-reinforcer choice in the terminal delay block (Block 5 for the Ascending Group and Block 1 for the Descending Group), during the last five delay-discounting sessions, was greater than $50 \%$. In the days separating probe sessions, delay-discounting sessions were conducted. Once the criterion for stable responding during probe sessions was met within one or two sessions, probe sessions were no longer conducted. For two rats in the Descending Group, SB-3 and SB-7, the stability criterion for probe sessions was never met within two sessions. The minimum number of consecutive probe sessions required for responding to meet the stability criterion was four sessions for SB-3 and seven sessions for SB-7.

Delay-Discounting Procedure. The delay-discounting procedure and criteria for stable choice was the same as was used in Experiment 1. Before $d$-amphetamine administration and after equal-delay probe sessions, delay-discounting sessions were conducted for a minimum of 10 sessions and until choice was stable.

Acute Drug Administration. After the stability criteria for baseline delay-discounting functions (described in Experiment 1) were met, effects of acute administration of $d$ amphetamine on delay discounting were assessed. Throughout the acute drug administration phase, Mondays and Thursdays served as control days and no injections were administered. If delay-discounting functions were stable (when $80 \%$ or greater larger-outcome choice in 0 -s block and delay-discounting functions were assessed by visual inspection to be similar to baseline delay-discounting functions) during control sessions, saline or $d$-amphetamine was administered by ip injection immediately before the start of the session on Tuesdays and Fridays. Prior to administration of $d$-amphetamine, saline was administered in at least two sessions to allow rats to habituate to ip injection and, therefore, reduce disruption in lever-pressing resulting 
from the injection procedure. If injection of saline alone disrupted lever pressing, saline was administered on consecutive Tuesdays and Fridays until percent larger-reinforcer choice met stability criteria described for control days. $d$-Amphetamine sulfate salt was dissolved in a $0.9 \%$ saline solution $(1.0 \mathrm{mg} / \mathrm{ml})$ and $d$-amphetamine was administered in an injection volume of 1.0 $\mathrm{ml} / \mathrm{kg}$. In order to determine a dose-response function, the following doses were tested: 0.0 (saline), $0.1,0.3,1.0$, and $1.8 \mathrm{mg} / \mathrm{kg}$. Sessions with administration of $1.8 \mathrm{mg} / \mathrm{kg} d$-amphetamine are not presented and were not included in data analysis, as control was already shown to be lost with $1.0 \mathrm{mg} / \mathrm{kg} d$-amphetamine resulting in less than $80 \%$ larger-reinforcer choice with the 0 -s delay value for all rats. Half of the rats $(\mathrm{n}=2)$ in the Ascending Group and half of the rats $(\mathrm{n}=2)$ in the Descending Group received doses in an increasing order, starting with $0.1 \mathrm{mg} / \mathrm{kg}$. The other half of the rats in the Ascending Group and the Descending Group received doses in a decreasing order, starting with $1.8 \mathrm{mg} / \mathrm{kg}$. A minimum of two determinations of each dose was obtained. Additional determinations of a dose were obtained if visual inspection of the data revealed substantial variability in behavioral effects during sessions following the first two administrations. Substantial variability included different effects (increases, decrease, or no change) of a given dose on delay discounting across the first two determinations of that dose. Also, additional determinations of a dose were obtained if choice was less than $80 \%$ at the 0 -s delay value with one of the first two administrations, but greater than $80 \%$ with the other. Data from sessions in which the dose resulted in lever-press suppression, defined as omission of more than six free-choice trials within a session, was not included in the analysis of the data.

Data Analysis. Mean sessions to pass equal-delay probes were compared between the Ascending and Descending Groups using an independent-means t-test. It is important to note that a maximum of 20 consecutive probe sessions was set. Therefore, if the stability criterion for 
probe sessions was not met within 20 sessions, 20 was recorded as the number of consecutive sessions required for responding to meet the stability criterion for probe sessions (at least $80 \%$ larger-reinforcer choice in four out of five blocks and at least $67 \%$ larger-reinforcer choice in one block). Mean percent larger-reinforcer choice with each delay value when saline and multiple doses of $d$-amphetamine $(0.1,0.3$, and $1.0 \mathrm{mg} / \mathrm{kg})$ were administered was the primary dependent variable. Means are comprised of percent larger-reinforcer choice during free-choice trials. Mean area under the curve at each dose of $d$-amphetamine was calculated as described in Experiment 1. Also, mean percent change in area under the curve, relative to area under the curve at saline, was calculated at each dose of $d$-amphetamine. Mean area under the curve was analyzed using a 2 x 5 (Delay Order [ascending, descending] x dose [control, saline, $0.1 \mathrm{mg} / \mathrm{kg}$ $0.3 \mathrm{mg} / \mathrm{kg}, 1.0 \mathrm{mg} / \mathrm{kg}])$ mixed ANOVA.

\section{Results}

Equal-Delay Probe Sessions. To ensure sensitivity to the magnitude difference between smaller (one pellet) and larger (three pellets) reinforcers, equal-delay probe sessions were conducted prior to $d$-amphetamine administration. Few or no response omissions were recorded for each rat during probe sessions. Fewer sessions per equal-delay probe exposure were required for choice to meet the stability criterion with the Ascending Group (mean $=1.88, \pm 0.32$ ) relative to the Descending Group $($ mean $=8.77, \pm 2.81)$. An independent-means t-test, however, revealed no statistically significant difference in mean number of sessions required to achieve stable choice during equal-delay probe sessions between groups (Ascending versus Descending), $t(6)=-2.44, p=.05$. The 20 consecutive probe sessions maximum was never met for any rat in the Ascending Group, with the greatest number of consecutive probe sessions required for choice to meet the stability criterion being four sessions for rat SB-6. The 20 consecutive sessions 
maximum was, however, met once each for two of four rats in the Descending Group (rats SB-3 and SB-7). Thus, it is impossible to know how many sessions it would have taken for responding to meet the stability criterion for these two rats.

Delay Discounting and $d$-Amphetamine. Figure 3 shows delay-discounting functions at saline and various doses of $d$-amphetamine for the Ascending (left panels) and Descending (right panels) Groups. Delay-discounting functions were generated using mean percent largerreinforcer choice at saline and each dose of $d$-amphetamine from the four rats in each group (see Appendix B for mean percent larger-reinforcer choice for each rat at each dose). Few to no response omissions were recorded for all rats. As with Experiment 1, generally, as the delay to larger-reinforcer delivery increased, choice for the larger reinforcer decreased (filled symbols). Administration of 0.1 and $0.3 \mathrm{mg} / \mathrm{kg} d$-amphetamine did not alter delay-discounting functions for either the Ascending or Descending Groups (see Figure 3). At saline, $0.1 \mathrm{mg} / \mathrm{kg} d$-amphetamine, and $0.3 \mathrm{mg} / \mathrm{kg} d$-amphetamine, mean percent larger-reinforcer choice with the 0 -s delay value was $80 \%$ or greater for all rats, with the exception of rat SB-1 in the Ascending Group at 0.1 $\mathrm{mg} / \mathrm{kg} d$-amphetamine and rat SB-3 in the Descending Group at $0.3 \mathrm{mg} / \mathrm{kg} d$-amphetamine (indicated by bolded values in Table 2). At $1.0 \mathrm{mg} / \mathrm{kg} d$-amphetamine, however, mean percentlarger reinforcer choice was less than $80 \%$ with the 0 -s delay value for all rats in both the Ascending and Descending Groups and a flattening of the delay-discounting function was observed, particularly for the Descending Group. Flattening of the delay-discounting function suggests indifference between the two choice outcomes.

The top panel of Figure 4 shows mean area under the curve at each dose of $d$ amphetamine for the Ascending (black bars) and Descending (cross-hatched bars) Groups. At each dose of $d$-amphetamine, mean area under the curve for each group was calculated using 
area under the curve for each rat in the group (see Table 2 for individual data). Dose-dependent decreases or no change in mean area under the curve, relative to saline, were observed for both groups at $0.1,0.3$, and $1.0 \mathrm{mg} / \mathrm{kg}$ doses of $d$-amphetamine. Decreases in mean area under the curve at $1.0 \mathrm{mg} / \mathrm{kg} d$-amphetamine are difficult to interpret due to loss of control (less than $80 \%$ mean larger-reinforcer choice) with the 0-s delay value for all rats in the Ascending and Descending Groups. The bottom panels of Figure 4 show mean percent of area under the curve at saline for the Ascending (left panel) and Descending (right panel) Groups at 0.1, 0.3, and 1.0 $\mathrm{mg} / \mathrm{kg} d$-amphetamine. For the Ascending and Descending Groups, mean percent of area under the curve at saline dose dependently decreased at $0.1,0.3$, and $1.0 \mathrm{mg} / \mathrm{kg} d$-amphetamine. Mean percent of area under the curve at saline at each dose of $d$-amphetamine was similar for the Ascending and Descending Groups (see Figure 4), indicating that effects of $d$-amphetamine on area under the curve did not differ as a function of order of delay presentation (ascending versus descending). To supplement the visual analysis of mean area under the curve at each dose of $d$ amphetamine (see top panel of Figure 4), a 2 (Delay Order) x 5 (Dose) mixed ANOVA was conducted. The ANOVA revealed no significant main effect of delay order, $\mathrm{F}(1,6)=1.12, p=$ .332 , and no significant delay order $\mathrm{x}$ dose interaction, $\mathrm{F}(3,18)=1.33, p=.287$. There was a significant main effect of dose, $\mathrm{F}(4,24)=12.60, p<.001$. Pairwise comparisons showed significant decreases in mean area under the curve, relative to saline, at $0.3(p=.014)$ and $1.0(p$ $=.002) \mathrm{mg} / \mathrm{kg} d$-amphetamine. According to both visual inspection and statistical analyses, generally, $d$-amphetamine resulted in dose-dependent decreases in area under the curve with 0.3 and $1.0 \mathrm{mg} / \mathrm{kg}$ doses of $d$-amphetamine, regardless of order of delay presentation. 


\section{Discussion}

In the present experiment, delay discounting was maintained such that as the delay to larger-reinforcer delivery increased, choice for the larger reinforcer decreased. This pattern of choice is consistent with patterns reported in Experiment 1 of the present study and numerous earlier studies using discrete-trials, delay-discounting procedures (e.g. Anderson \& Diller, 2010; Evenden \& Ryan, 1996; Madden, Smith, Brewer, Pinkston, \& Johnson, 2008; Slezak \& Anderson, 2011). In addition, consistent with results reported by Slezak and Anderson (2009) and Experiment 1 of the present study, delay discounting during control and saline sessions did not differ as a function of order of delay presentation.

During equal-delay probe sessions for the Descending Group, the delay to reinforcer delivery may have weakened control of the magnitudes of the smaller (one food pellet) and the larger (three food pellets) reinforcers on choice. The delay to both reinforcers may have weakened control by decreasing the discriminability between the smaller and the larger reinforcers. In the context of discrete-trials, delay-discounting procedures, as the delay to delivery of the larger reinforcer increases, the larger reinforcer's efficacy, or ability to maintain responding, decreases (cf. Mazur, 1987). The delay to delivery of smaller and larger reinforcers during equal-delay probe sessions for the Descending group, decreased percent-larger reinforcer choice to less than $50 \%$ during delay-discounting sessions, thus resulting in the three, delayed food pellets maintaining less percent choice than one, immediate food pellet. During equal-delay probe sessions, the delay in effect may have reduced the efficacy of each reinforcer by a set proportion. For example, if the delay degraded the efficacy of each reinforcer by half, then, rather than choosing between one food pellet and three food pellets, functionally rats may have been choosing between one half a food pellet and one and a half food pellets. In this example, the 
relative difference between the magnitudes of the smaller and the larger reinforcers is the same in both the immediate and delayed probe conditions, with the larger reinforcer being three times the magnitude of the smaller reinforcer. The absolute difference in smaller and larger reinforcer magnitudes, however, is two in the immediate condition, but only one in the delayed condition. A smaller absolute magnitude difference between the smaller and the larger reinforcers may have resulted in less discrimination between the two outcomes during equal-delay probe sessions for the Descending Group. This provides one possible explanation for why the 20 consecutive probe session maximum was met for two of four rats in the Descending Group, but was never met for any rats in the Ascending Group. Future research is necessary to investigate this possible explanation. For instance, if the delay to delivery of the smaller and the larger reinforcers was varied across conditions, this explanation predicts a positive correlation between the number of sessions required to achieve stable choice and the duration of delay to delivery of both reinforcers.

Larger doses of $d$-amphetamine $(0.3$ and $1.0 \mathrm{mg} / \mathrm{kg})$ decreased mean percent largerreinforcer choice and mean area under the curve. Though, effects of $d$-amphetamine on delay discounting reported in the literature are mixed, the results reported in the present study are consistent with $d$-amphetamine effects reported by several other studies (e.g. Evenden \& Ryan, 1996; Slezak \& Anderson, 2009). Also consistent with Slezak and Anderson, decreases in mean percent larger-reinforcer choice and area under the curve with $1.0 \mathrm{mg} / \mathrm{kg} d$-amphetamine included significant decreases in larger-reinforcer choice with the 0 -s delay value. This outcome makes interpretation of effects of $1.0 \mathrm{mg} / \mathrm{kg} d$-amphetamine on delay discounting difficult. With the procedure described in the present study, choice is being controlled by both reinforcer amount and delay to larger-reinforcer delivery. When choice with the 0 -s delay value is not 
disrupted (when choice for the larger-reinforcer is $80 \%$ or greater), this provides evidence that the drug is not disrupting sensitivity to reinforcer amount. When choice with the 0 -s delay block is disrupted, however, it is impossible to determine if changes in delay discounting with 1.0 $\mathrm{mg} / \mathrm{kg} d$-amphetamine were due to changes in control by reinforcer amount, delay, or both.

Future research investigating the impact of $d$-amphetamine on control by reinforcer amount could include administration of $d$-amphetamine prior to 0 -s probe sessions. With 0 -s probes, at baseline, choice would be near exclusive for the larger reinforcer and there would be no delay. Therefore, any changes in larger-reinforcer choice with $d$-amphetamine administration would show change in control by reinforcer amount.

Pitts and Febbo (2004) used a concurrent-chains procedure and quantitative analyses to describe effects of methamphetamine on sensitivity to both reinforcer amount and delay to reinforcer delivery. The authors arranged delivery of a larger, more delayed reinforcer according to a fixed-time (FT) schedule in one terminal link and delivery of a smaller, more immediate reinforcer according to a different FT schedule in the other terminal link. The duration of the FT value in effect in the terminal link with the larger, more delayed reinforcer increased across blocks within a session, but the duration of the FT value was held constant in the other terminal link. Response rates and time allocation on each key during the initial link were analyzed using a logarithmic equation derived from the matching law and hyperbolic discounting models. For sessions when drug was administered, relative to saline, differences in the slope of fitted lines represented changes in sensitivity to delay to reinforcer delivery, whereas changes in the yintercept represented changes in sensitivity to reinforcer amount. Pitts and Febbo concluded that, generally, intermediate doses of methamphetamine decreased sensitivity to delay to reinforcer delivery, and sometimes decreases in sensitivity to reinforcer delay were accompanied by 
decreases in sensitivity to reinforcer amount. For future research, the procedure and quantitative analyses described by Pitts and Febbo would be particularly useful for describing effects of $d$ amphetamine when administration results in disruption of larger-reinforcer choice with the 0-s delay value in the context of a discrete-trials, delay-discounting procedure.

When baseline area under the curve did not differ as a function of order of delaypresentation, Slezak and Anderson reported significantly greater decreases in area under the curve with administration of larger doses of $d$-amphetamine when delays were presented in a descending, relative to ascending, order. This finding was not replicated in the present study, as all effects of $d$-amphetamine on area under the curve were consistent across the Ascending and Descending Groups. Differences in procedures used by Slezak and Anderson and the present study may account for the present study's failure to replicate the effect reported by Slezak and Anderson. The present study used a group-design in which each rat was exposed to only one order of delay presentation (ascending or descending), whereas Slezak and Anderson used a within-subject design in which all rats were exposed to both ascending and descending order of delay presentations and the order of delay presentation in effect during each session was randomly determined prior to the start of the session. Future research should focus on determining under what experimental conditions effects of $d$-amphetamine on delay discounting differ as a function of order of delay presentation.

\section{General Discussion and Conclusion}

In Experiments 1 and 2, delay discounting was observed in all rats. Generally, as the delay to delivery of the larger reinforcer increased, choice for the larger reinforcer decreased. This is consistent with a vast body of existing literature. There have been numerous studies investigating effects of $d$-amphetamine on delay discounting. Results from these studies have 
been mixed. Consistent with several existing studies, the current study found decreases largerreinforcer choice with administration of $d$-amphetamine. However, in the present study it is difficult to determine if larger doses of $d$-amphetamine altered control by reinforcer amount or delay to reinforcer delivery.

Consistent with the findings of Slezak and Anderson (2009), Experiment 1 found no differences in baseline delay discounting as a function of either ascending or descending order of delay presentation and Experiment 2 found dose-dependent decreases in area under the curve with administration of $d$-amphetamine. However, Experiment 2 failed to replicate Slezak and Anderson's finding of significantly larger decreases in area under the curve with descending, rather than ascending, order of delay presentation. Ultimately, when the present study controlled for history of exposure to different order of delay presentations, order of delay presentation (ascending versus descending) did not impact levels of baseline delay discounting or effects of $d$ amphetamine on delay discounting, thus ruling out order of delay presentation as a procedural variable impacting baseline delay discounting or effects of $d$-amphetamine on delay discounting. This is a positive finding for researchers using delay-discounting procedures or those designing interventions grounded in the large body of delay-discounting literature. Most studies using discrete-trials, delay-discounting procedures have presented delays to larger-reinforcer delivery in an ascending order. The present study's consistent replication of delay discounting and consistent drug effects on delay discounting regardless of order of delay presentation suggests that order of delay presentation may not impact choice in the context of within-session, discretetrials delay-discounting procedures. 


\section{References}

Ainslie, G. (1975). Specious reward: A behavioral theory of impulsiveness and impulse control. American Psychological Association, 82, 463-496.

American Psychiatric Association (2000). Diagnostic and statistical manual of mental disorders ( $4^{\text {th }}$ ed., text revision). Washington, DC: Author.

Anderson, K.G. \& Diller, J.W. (2010). Effects of acute and repeated nicotine administration on delay discounting in Lewis and Fischer 344 rats. Behavioural Pharmacology, 21, $754-764$.

Anderson, K.G. \& Woolverton, W.L. (2005). Effects of clomipramine on self-control choice in Lewis and Fisher 344 rats. Pharmacology, Biochemistry, and Behavior, 80, 387-393.

Anderson, K.G., \& Woolverton, W.L. (2003). Effects of dose and infusion delay on cocaine self-administration choice in rhesus monkeys. Psychopharmacology, 167, 424-430.

Bickel, W.K., Odum, A., \& Madden, G. (1999). Impulsivity and cigarette smoking: delay discounting in current, never, and ex-smokers. Pschopharmacology, 146, 447-454.

Cardinal, R.N., Robbins, T.W., \& Everitt, B.J. (2000). The effects of $d$-amphetamine, chlordiazepoxide, $\alpha$-flupenthixol and behavioural manipulations on choice of signalled and unsignalled delayed reinforcement in rats. Psychopharmacology, 152, 362-375.

Charrier, D. \& Thiebot, M.H. (1996). Effects of psychotropic drugs on rat responding in an operant paradigm involving choice between delayed reinforcers. Pharmacology, Biochemistry, and Behavior, 54, 149-157.

Coffey, S.F., Gudleski, G. D., Saladin, M.E., \& Brady, K.T. (2003). Impulsivity and rapid discounting of delayed hypothetical reward in cocaine-dependent individuals. 
Experimental and Clinical Psychopharmacology, 11, 18-25.

De Wit, H., Enggasser, J.L., \& Richards, J.B. (2002). Acute administration of $d$-amphetamine decreases impulsivity in healthy volunteers. Neuropsychopharmacology, 27, 813-825.

Diller, J.W., Saunders, B.T., \& Anderson, K.G. (2008). Effects of acute and repeated administration of caffeine on temporal discounting in rats. Pharmacology, Biochemistry, and Behavior, 89, 546-555.

Evenden, J.L. \& Ryan, C.N. (1996). The pharmacology of impulsive behaviour in rats: the effects of drugs on response choice with varying delays of reinforcement. Psychopharmacology, 128, 161-170.

Fox, A.T., Hand, D.J., \& Reilly, M.P. (2008). Impulsive choice in a rodent model of attentiondeficit/hyperactivity disorder. Behavioural Brain Research, 187, 146-152.

Green, L., Fry, A.F., \& Myerson, J. (1994). Discounting of delayed rewards: A life-span comparison. Psychological Science, 5, 33-36.

Hand, D.J., Fox, A.T., \& Reilly, M.P. (2009). Differential effects of $d$-amphetamine on impulsive choice in spontaneously hypertensive and Wistar-Kyoto rats. Behavioural Pharmacology, 20, 549-553.

Logue, A.W. (1988). Research on self-control: An integrating framework. Behavioral and Brain Sciences, 11, 665-709.

Madden, G.J., Smith, N.G., Brewer, A.T., Pinkston, J.W., \& Johnson, P.S. (2008). Steady-state assessment of impulsive choice in Lewis and Fisher 344 rats: Between-condition delay manipulations. Journal of the Experimental Analysis of Behavior, 90, 333-344.

Mazur, J. E. (1987). An adjusting procedure for studying delayed reinforcement. In M. L. Commons, J. E. Mazur, J. A. Nevin, and H. Rachlin (Eds.), Quantitative analyses of 
behavior: Vol. 5. The effect of delay and intervening events on reinforcement value (pp. 55-73). Hillsdale, NJ: Erlbaum.

Myerson, J., Green, L., \& Warusawitharana, M. (2001). Area under the curve as a measure of discounting. Journal of the Experimental Analysis of Behavior, 76, 235-243.

Myerson, J., \& Green, L. (1995). Discounting of delayed rewards: Models of individual choice. Journal of the Experimental Analysis of Behavior, 64, 263-276.

Odum, A.L., Madden, G.J., Badger, G.J., \& Bickel, W.K. (2000). Needle sharing in opioddependent outpatients: psychological processes underlying risk. Drug and Alcohol Dependence, 60, 259-266.

Perry, J.L., Stairs, D.J., \& Bardo, M.T. (2008). Impulsive choice and environmental enrichment: Effects of $d$-amphetamine and methylphenidate. Behavioural Brain Research, 193, 48-54.

Petry, N.M. (2001a). Delay discounting of money and alcohol in actively-using alcoholics, currently abstinent alcoholics, and controls. Psychopharmacology, 154, 243-250.

Perty, N.M. (2001b). Pathological gamblers, with and without substance abuse disorders, discount delayed rewards at high rates. Journal of Abnormal Psychology, 110, 482-487.

Pitts, R.C. \& Febbo, S.M. (2004). Quantitative analyses of methamphetamine's effects on selfcontrol choices: Implication for elucidating behavioral mechanisms of drug action. Behavioural Processes, 66, 213-233.

Richards, J.B., Mitchell, S. H. , de Witt, H., \& Seiden, S.L. (1997). Determination of discounting functions in rats with an adjusting amount procedure. Journal of the Experimental Analysis of Behavior, 67, 353-366.

Scheres, A., Tontsch, C., Thoeny, A.L., \& Kaczkurkin, A. (2010). Temporal reward 
discounting in attention-deficit/hypersactivity disorder: the contribution of symptom domains, reward magnitude, and session length. Biological Psychiatry, 67, 641-648.

Slezak, J.M. \& Anderson, K.G. (2011). Effects of acute and chronic methylphenidate on delay discounting. Pharmacology, Biochemistry and Behavior, 99, 545-551.

Slezak, J.M. \& Anderson, K.G. (2009). Effects of variable training, signaled and unsignaled delays, and $d$-amphetamine on delay-discounting functions. Behavioural Pharmacology, 20, 424-436.

Wade, T.R., de Witt, H., \& Richards, J.B. (2000). Effects of dopaminergic drugs on delayed reward as a measure of impulsive behavior in rats. Psychopharmacology, 150, 90-101.

Weller, R.E, Cook III, E.W., Avsar, K.B., \& Cox, J.E. (2008). Obese women show greater delay discounting than healthy-weight women. Appetite, 51, 563-569.

Winstanley, C.A., Dalley, J.W., Theobald, D.E., \& Robbins, T.W. (2003). Global 5-HT depletion attenuates the ability of amphetamine to decrease impulsive choice on a delaydiscounting task in rats. Psychopharmacology 170, 320-331.

Woolverton, W.L. \& Anderson, K.G. (2006). Effects of delay to reinforcement on the choice between cocaine and food in rhesus monkeys. Psychopharmacology, 186, 99-106. 
Table 1

Delay order, terminal delay value, sessions to stability, baseline area under the curve, and indifference points for individual rats

\begin{tabular}{cccccc}
\hline Rat & $\begin{array}{c}\text { Delay } \\
\text { Order }\end{array}$ & $\begin{array}{c}\text { Terminal } \\
\text { Delay (s) }\end{array}$ & $\begin{array}{c}\text { Sessions to } \\
\text { Stability }\end{array}$ & $\begin{array}{c}\text { Area Under } \\
\text { the Curve }\end{array}$ & $\begin{array}{c}\text { Indifference } \\
\text { Point (s) }\end{array}$ \\
\hline SB-1 & Ascending & 60 & 51 & 0.70 & 47.13 \\
SB-2 & Ascending & 60 & 66 & 0.35 & 12.53 \\
SB-5 & Ascending & 60 & 49 & 0.63 & 45.66 \\
SB-6 & Ascending & 60 & 30 & 0.39 & 20.11 \\
Mean (SEM) & & & $\mathbf{4 9 . 0 0 ( 7 . 3 8 )}$ & $\mathbf{0 . 5 2 ( 0 . 0 9 )}$ & $\mathbf{3 1 . 3 6 ( 8 . 8 2 )}$ \\
SB-3 & Descending & 60 & 87 & 0.57 & 42.27 \\
SB-4 & Descending & 60 & 38 & 0.61 & 40.58 \\
SB-7 & Descending & 60 & 148 & 0.43 & 23.25 \\
SB-8 & Descending & 40 & 36 & 0.46 & 17.02 \\
Mean (SEM) & & & $\mathbf{7 7 . 2 5 ( 2 6 . 3 7 )}$ & $\mathbf{0 . 5 2 ( 0 . 0 4 )}$ & $\mathbf{3 0 . 7 8 ( 6 . 2 9 )}$ \\
\hline
\end{tabular}


Table 2

Area under the curve during control sessions and with each dose of $d$-AMP $(\mathrm{mg} / \mathrm{kg})$ for each rat

\begin{tabular}{ccccccc} 
Delay Order & Rat & Control & Saline & 0.1 & 0.3 & 1.0 \\
\hline \multirow{2}{*}{ Ascending } & SB-1 & 0.46 & 0.53 & $\mathbf{0 . 4 6}$ & 0.46 & $\mathbf{0 . 3 3}$ \\
& SB-2 & 0.28 & 0.27 & 0.34 & 0.22 & $\mathbf{0 . 1 7}$ \\
& SB-5 & 0.52 & 0.48 & 0.43 & 0.50 & $\mathbf{0 . 3 0}$ \\
& SB-6 & 0.47 & 0.46 & 0.36 & 0.40 & $\mathbf{0 . 4 8}$ \\
Mean & & 0.43 & 0.44 & 0.40 & 0.40 & 0.32 \\
SEM & & 0.05 & 0.06 & 0.03 & 0.06 & 0.06 \\
Descending & SB-3 & 0.45 & 0.39 & 0.33 & $\mathbf{0 . 3 5}$ & $\mathbf{0 . 2 0}$ \\
& SB-4 & 0.62 & 0.64 & 0.64 & 0.56 & $\mathbf{0 . 5 4}$ \\
& SB-7 & 0.46 & 0.44 & 0.43 & 0.39 & $\mathbf{0 . 2 0}$ \\
& SB-8 & 0.70 & 0.65 & 0.67 & 0.64 & $\mathbf{0 . 4 1}$ \\
Mean & & 0.56 & 0.53 & 0.52 & 0.49 & 0.34 \\
SEM & & 0.06 & 0.07 & 0.08 & 0.06 & 0.09 \\
\hline
\end{tabular}

Note: Bolded AUC values were derived from delay-discounting functions in which mean percent larger-reinforcer choice was less than $80 \%$ in the 0 -s control block. SEM is standard standard error of the mean. 


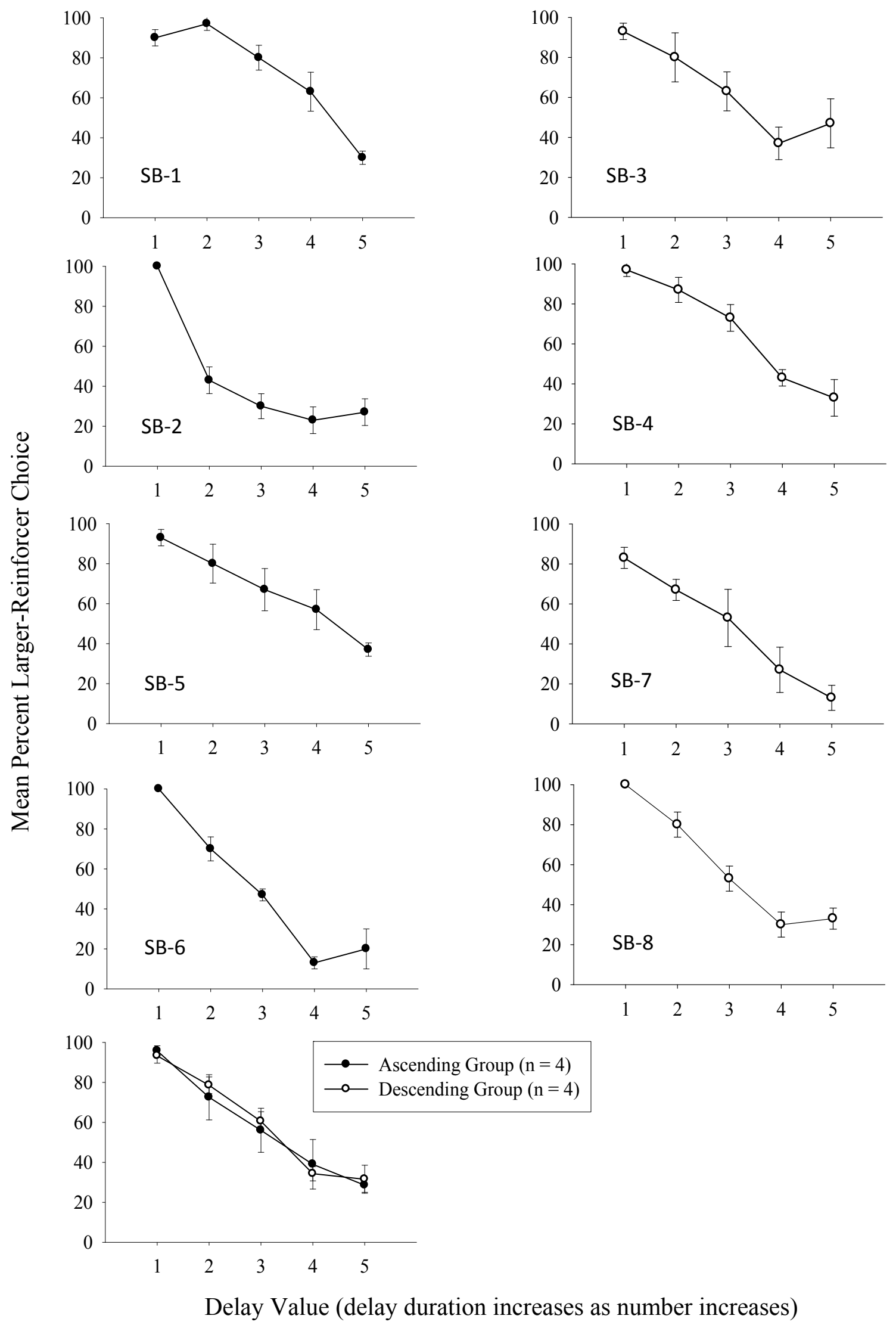


Figure 1. Mean percent larger-reinforcer choice for each rat and the Ascending and Descending Groups. All panels show mean percent larger-reinforcer choice on the y-axis and delay value on the $\mathrm{x}$-axis (larger values represent longer delays). For rats SB-1 through SB-7, delay values along the $\mathrm{x}$-axis were $0,10,20,40$, and $60 \mathrm{~s}$. For rat SB-8, delay values were $0,5,10,20$, and 40 s. Mean percent larger-reinforcer choice for each rat in the Ascending Group is represented by filled circles in the first four left panels. Mean percent larger-reinforcer choice each rat in the Descending Group (DG) is represented by open circles in the four right panels. Bottom, Left Panel: Mean percent larger-reinforcer choice as a function of delay value is presented for the Ascending Group and Descending Groups. Mean percent larger-reinforcer choice is represented by filled symbols for rats in the Ascending Group and open symbols for rats in the Descending Group. All error bars represent \pm SEM. 

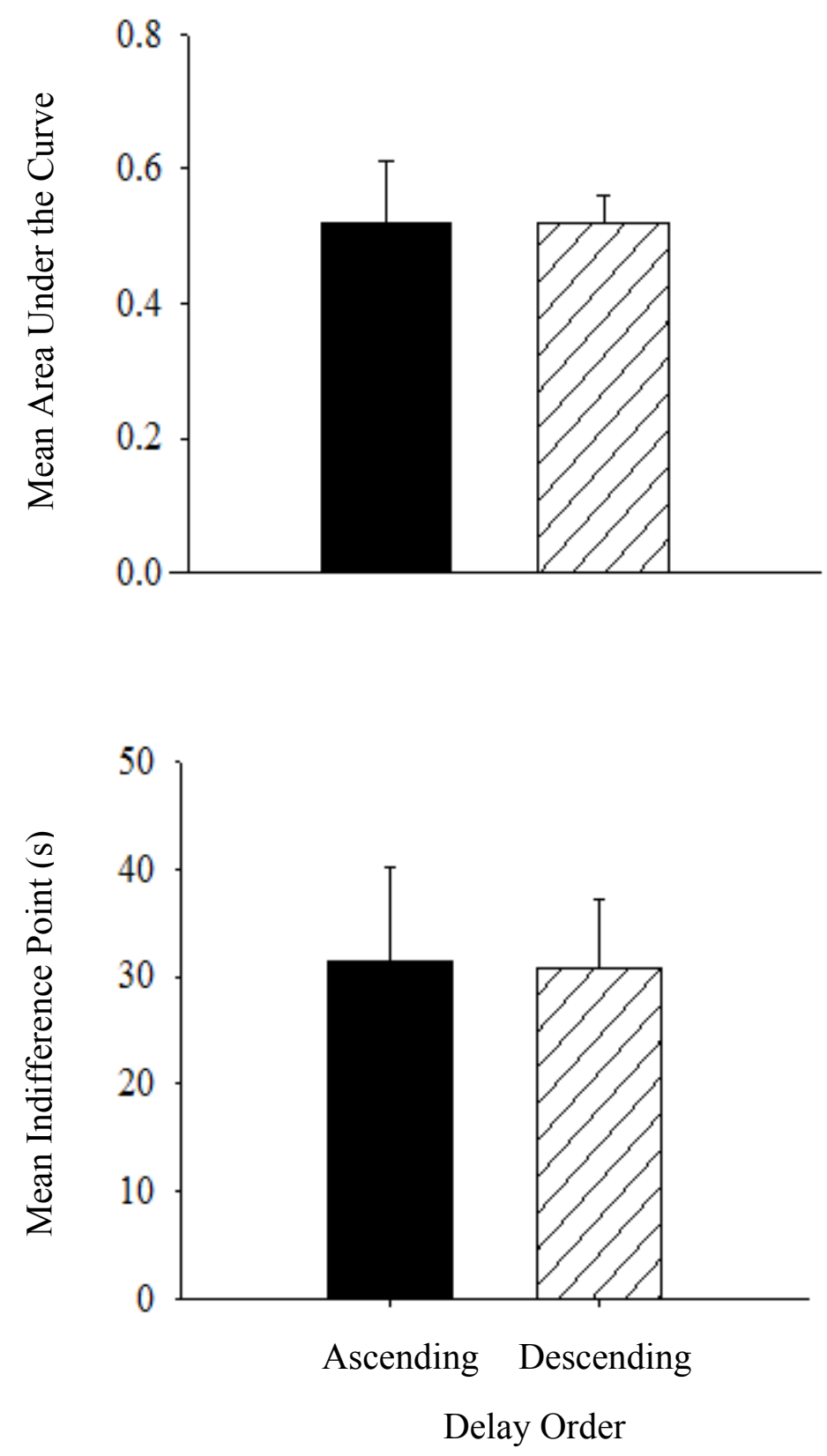

Figure 2. Top Panel: Mean area under the curve is shown by a black bar for rats in the Ascending Group and a cross-hatched bar for rats in the Descending Group. Bottom Panel: Mean indifference point (in s) is shown by a black bar for rats in the Ascending Group and a cross-hatched bar for rats in the Descending Group. All error bars represent + SEM. 
Ascending Group $(n=4)$

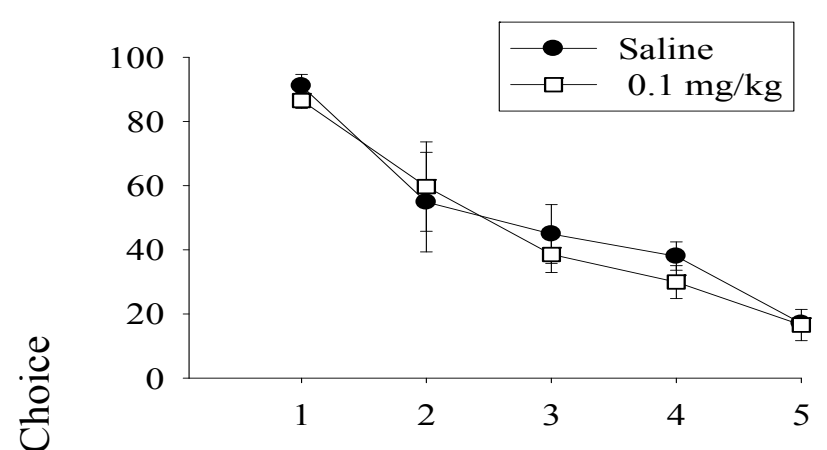

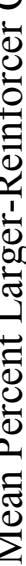
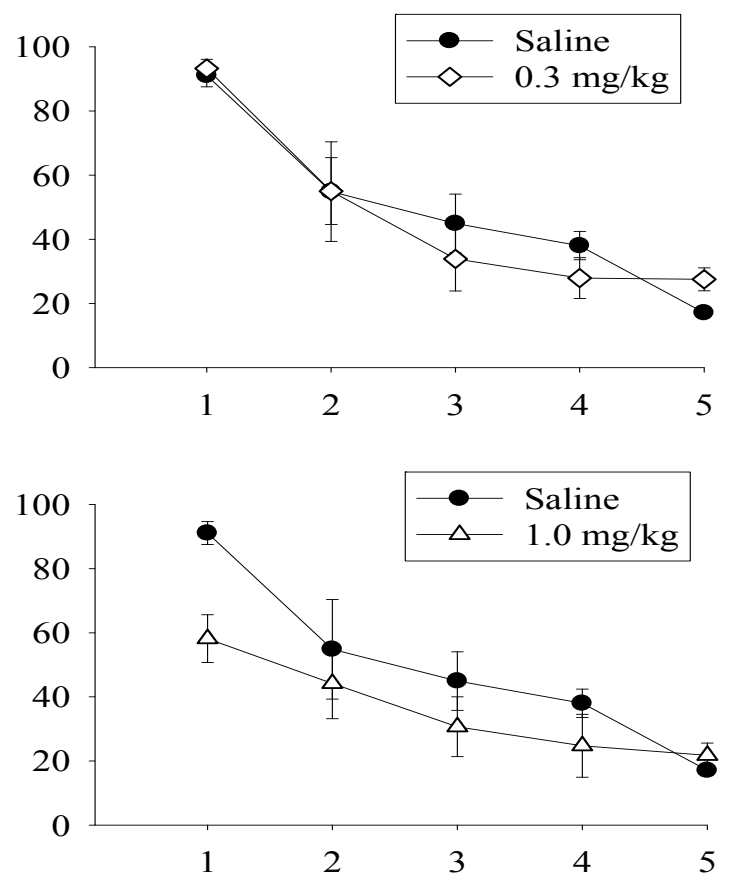

Descending Group $(n=4)$
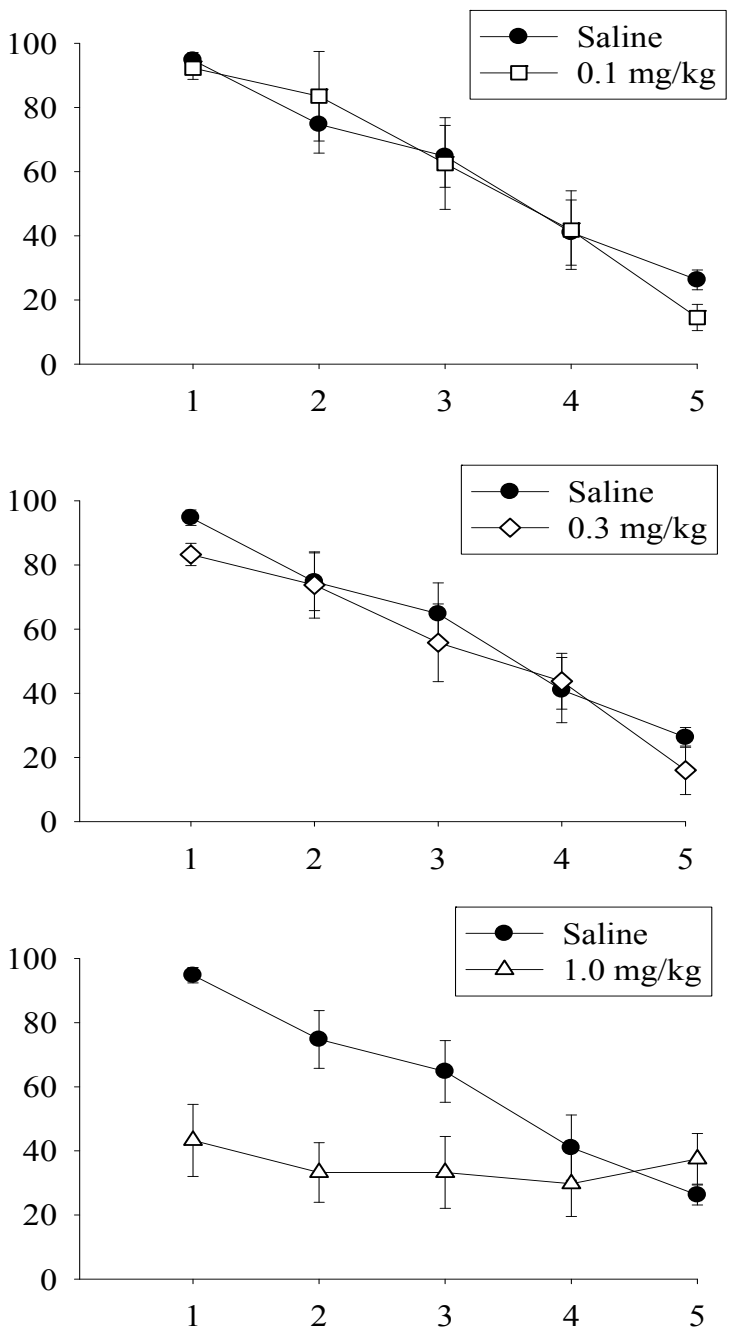

Delay Value (delay duration increases as number increases)

Figure 3. Mean percent-larger reinforce choice (y-axis) at saline (filled circles) and doses of $d$ amphetamine, including $0.1 \mathrm{mg} / \mathrm{kg}$ (open squares), $0.3 \mathrm{mg} / \mathrm{kg}$ (open diamonds), and $1.0 \mathrm{mg} / \mathrm{kg}$ (open triangles) is shown as a function of delay value (x-axis) for the Ascending (left panels) and Descending (right panels) Groups. All error bars represent \pm SEM. 

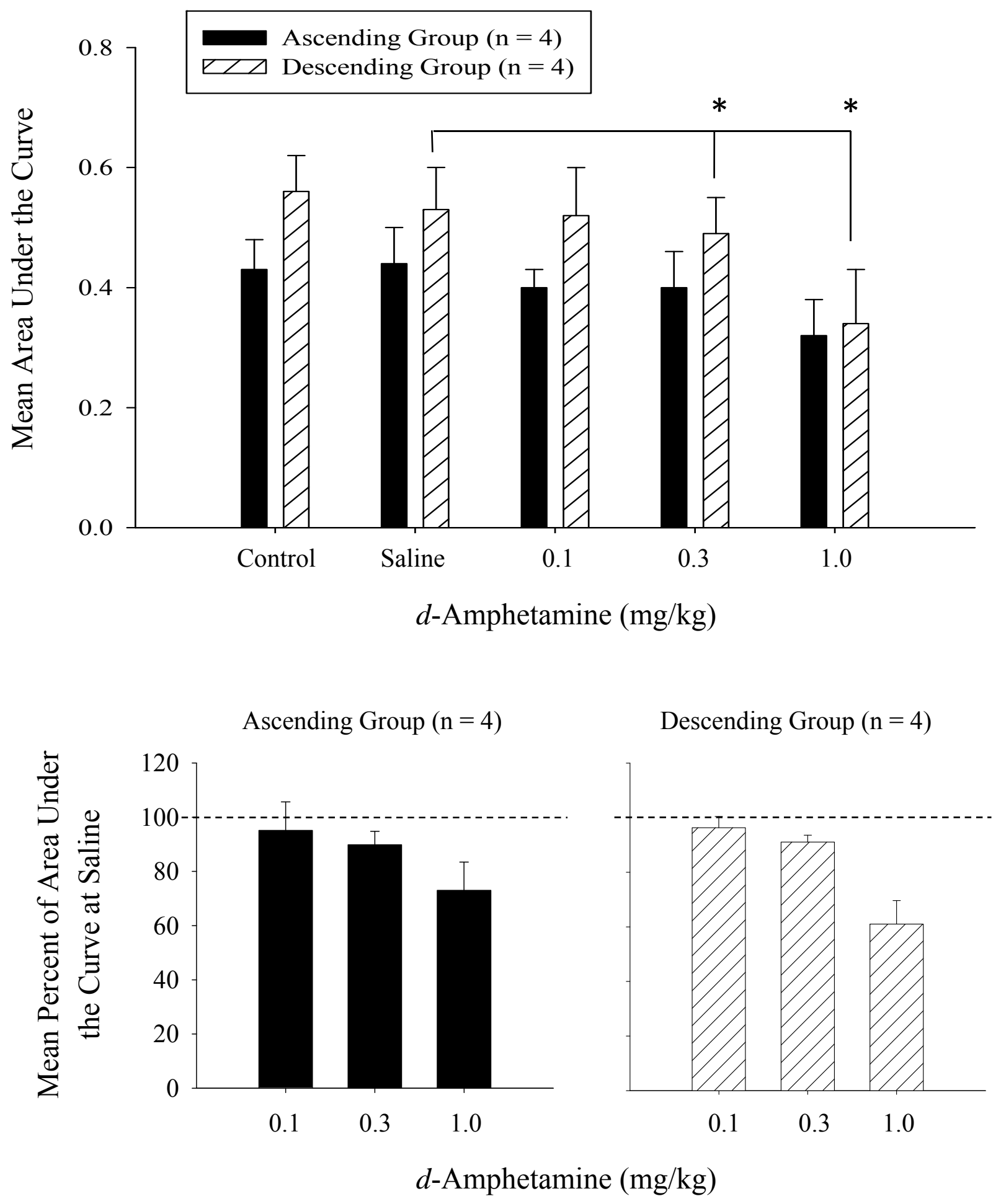

Figure 4. Top Panel: Mean area under the curve (y-axis) is presented as a function of dose of $d$ amphetamine in $\mathrm{mg} / \mathrm{kg}$ (x-axis) for Ascending (black bars) and Descending (cross-hatched bars) Groups. Asterisks indicate doses at which mean area under the curve was significantly lower, 
relative to saline, regardless of delay order. Bottom Panels: Mean percent of area under the curve at saline (y-axis) is presented as a function of dose of $d$-amphetamine in $\mathrm{mg} / \mathrm{kg}$ ( $\mathrm{x}$-axis) for the Ascending (left panel/black bars) and Descending (right panel/cross-hatched bars) Groups. The dashed line represents no change from area under the curve at saline. Error bars in all panels represent + SEM 


\section{Appendix A}

Mean percent larger-reinforcer choice across last 5 days of stable responding for each rat

\begin{tabular}{|c|c|c|c|c|c|c|c|}
\hline \multicolumn{4}{|c|}{ Delay to Larger } & \multirow[b]{2}{*}{ Day 2} & \multirow[b]{2}{*}{ Day 3} & \multirow[b]{2}{*}{ Day 4} & \multirow[b]{2}{*}{ Day 5} \\
\hline Delay Order & Rat & Reinforcer (s) & Day 1 & & & & \\
\hline \multirow[t]{20}{*}{ Ascending } & SB-1 & 0 & 83.33 & 100.00 & 83.33 & 83.33 & 100.00 \\
\hline & & 10 & 100.00 & 100.00 & 83.33 & 100.00 & 100.00 \\
\hline & & 20 & 83.33 & 66.67 & 83.33 & 100.00 & 66.67 \\
\hline & & 40 & 83.33 & 33.33 & 66.67 & 50.00 & 83.33 \\
\hline & & 60 & 33.33 & 33.33 & 16.67 & 33.33 & 33.33 \\
\hline & SB-2 & 0 & 100.00 & 100.00 & 100.00 & 100.00 & 100.00 \\
\hline & & 10 & 50.00 & 33.33 & 33.33 & 66.67 & 33.33 \\
\hline & & 20 & 16.67 & 16.67 & 33.33 & 33.33 & 50.00 \\
\hline & & 40 & 33.33 & 33.33 & 33.33 & 16.67 & 0.00 \\
\hline & & 60 & 33.33 & 50.00 & 16.67 & 16.67 & 16.67 \\
\hline & SB-5 & 0 & 83.33 & 100.00 & 83.33 & 100.00 & 100.00 \\
\hline & & 10 & 66.67 & 83.33 & 50.00 & 100.00 & 100.00 \\
\hline & & 20 & 50.00 & 100.00 & 83.33 & 50.00 & 50.00 \\
\hline & & 40 & 66.67 & 66.67 & 66.67 & 16.67 & 66.67 \\
\hline & & 60 & 33.33 & 50.00 & 33.33 & 33.33 & 33.33 \\
\hline & SB-6 & 0 & 100.00 & 100.00 & 100.00 & 100.00 & 100.00 \\
\hline & & 10 & 50.00 & 83.33 & 66.67 & 83.33 & 66.67 \\
\hline & & 20 & 50.00 & 50.00 & 50.00 & 50.00 & 33.33 \\
\hline & & 40 & 0.00 & 16.67 & 16.67 & 16.67 & 16.67 \\
\hline & & 60 & 0.00 & 50.00 & 16.67 & 33.33 & 0.00 \\
\hline \multirow[t]{3}{*}{ Descending } & SB-3 & 0 & 100.00 & 100.00 & 100.00 & 83.33 & 83.33 \\
\hline & & 10 & 83.33 & 33.33 & 83.33 & 100.00 & 100.00 \\
\hline & & 20 & 83.33 & 50.00 & 66.67 & 83.33 & 33.33 \\
\hline
\end{tabular}




$\begin{array}{llllll}40 & 16.67 & 33.33 & 33.33 & 33.33 & 66.67 \\ 60 & 50.00 & 66.67 & 50.00 & 66.67 & 0.00\end{array}$

\begin{tabular}{|c|c|c|c|c|c|c|}
\hline \multirow[t]{5}{*}{ SB-4 } & 0 & 100.00 & 100.00 & 83.33 & 100.00 & 100.00 \\
\hline & 10 & 100.00 & 83.33 & 66.67 & 83.33 & 100.00 \\
\hline & 20 & 66.67 & 66.67 & 66.67 & 100.00 & 66.67 \\
\hline & 40 & 33.33 & 50.00 & 50.00 & 33.33 & 50.00 \\
\hline & 60 & 50.00 & 0.00 & 50.00 & 33.33 & 33.33 \\
\hline \multirow[t]{5}{*}{ SB-7 } & 0 & 83.33 & 100.00 & 83.33 & 83.33 & 66.67 \\
\hline & 10 & 66.67 & 83.33 & 66.67 & 50.00 & 66.67 \\
\hline & 20 & 16.67 & 100.00 & 33.33 & 50.00 & 66.67 \\
\hline & 40 & 33.33 & 0.00 & 66.67 & 16.67 & 16.67 \\
\hline & 60 & 33.33 & 0.00 & 16.67 & 0.00 & 16.67 \\
\hline \multirow[t]{5}{*}{ SB-8 } & 0 & 100.00 & 100.00 & 100.00 & 100.00 & 100.00 \\
\hline & 5 & 66.67 & 66.67 & 83.33 & 83.33 & 100.00 \\
\hline & 10 & 66.67 & 33.33 & 50.00 & 66.67 & 50.00 \\
\hline & 20 & 16.67 & 33.33 & 33.33 & 16.67 & 50.00 \\
\hline & 40 & 33.33 & 50.00 & 16.67 & 33.33 & 33.33 \\
\hline
\end{tabular}


Mean percent larger-reinforcer choice at control, saline, and tested doses of $d$-amphetamine (mg/kg) for each rat in Experiment 2

\begin{tabular}{|c|c|c|c|c|c|c|c|}
\hline Delay Order & Rat & $\begin{array}{c}\text { Delay to } \\
\text { Larger } \\
\text { Reinforcer }\end{array}$ & Control (SEM) & Saline (SEM) & 0.1 (SEM) & 0.3 (SEM) & 1.0 (SEM) \\
\hline \multirow[t]{20}{*}{ Ascending } & SB-1 & 0 & $91.67(1.91)$ & $83.33(5.27)$ & 79.17 (15.77) & $95.83(4.17)$ & 46.67 (19.29) \\
\hline & & 10 & 74.17 (3.08) & $83.33(7.45)$ & $66.67(6.80)$ & $75.00(15.96)$ & $36.67(16.16)$ \\
\hline & & 20 & $56.67(5.33)$ & $66.67(7.45)$ & $54.17(4.17)$ & $33.33(9.62)$ & $36.67(13.33)$ \\
\hline & & 40 & $25.00(4.60)$ & $40.00(4.08)$ & $41.67(8.33)$ & $37.50(14.23)$ & $30.00(6.24)$ \\
\hline & & 60 & 19.17 (3.68) & $13.33(8.16)$ & 4.17 (4.17) & $25.00(8.33)$ & $20.00(3.33)$ \\
\hline & SB-2 & 0 & $97.50(1.37)$ & $100.00(0.00)$ & $88.89(5.56)$ & $100.00(0.00)$ & $70.00(9.72)$ \\
\hline & & 10 & 25.83 & $11.11(8.24)$ & $22.22(11.11)$ & $27.78(5.56)$ & $16.67(9.13)$ \\
\hline & & 20 & $28.33(3.65)$ & $22.22(5.56)$ & $27.78(5.56)$ & $5.56(5.56)$ & $3.33(3.33)$ \\
\hline & & 40 & $16.67(3.20)$ & $25.00(7.14)$ & $33.33(19.25)$ & $11.11(5.56)$ & $13.33(6.24)$ \\
\hline & & 60 & $18.33(2.68)$ & $16.67(6.09)$ & $27.78(5.56)$ & $22.22(5.56)$ & $16.67(9.13)$ \\
\hline & SB-5 & 0 & $97.62(1.30)$ & 93.33 (4.08) & $88.89(5.56)$ & $87.50(12.50)$ & $44.44(5.56)$ \\
\hline & & 10 & $75.40(3.92)$ & $66.67(7.45)$ & $88.89(5.56)$ & $66.67(13.61)$ & $55.56(27.78)$ \\
\hline & & 20 & $49.21(5.08)$ & $46.67(6.24)$ & $33.33(19.25)$ & $50.00(15.21)$ & $38.89(14.70)$ \\
\hline & & 40 & $41.27(4.09)$ & $43.33(12.47)$ & $27.78(11.11)$ & $37.50(7.98)$ & $5.56(5.56)$ \\
\hline & & 60 & $30.16(3.92)$ & $16.67(9.13)$ & $16.67(0.00)$ & $37.50(7.98)$ & $33.33(19.25)$ \\
\hline & SB-6 & 0 & $96.21(1.52)$ & $87.50(4.17)$ & 88.89 (11.11) & 87.50 (7.98) & $72.22(5.56)$ \\
\hline & & 10 & $71.21(3.14)$ & $58.33(7.72)$ & $61.11(14.70)$ & $50.00(11.79)$ & $66.67(9.62)$ \\
\hline & & 20 & $50.76(4.17)$ & $43.75(7.67)$ & $38.89(5.56)$ & $45.83(17.18)$ & $44.44(11.11)$ \\
\hline & & 40 & 33.33 (3.95) & $43.75(9.42)$ & $16.67(16.67)$ & $00(15.96)$ & $50.00(9.62)$ \\
\hline & & 60 & $23.48(3.41)$ & $20.83(6.68)$ & $16.67(9.62)$ & $25.00(10.76)$ & $16.67(9.62)$ \\
\hline Descending & SB-3 & 0 & 96.88 (1.68) & $96.67(3.33)$ & $91.67(8.33)$ & $75.00(8.33)$ & $16.67(16.67)$ \\
\hline
\end{tabular}




\begin{tabular}{|c|c|c|c|c|c|c|}
\hline & 10 & $63.54(4.62)$ & $63.33(13.33)$ & $41.67(8.33)$ & $54.17(10.49)$ & $25.00(25.00)$ \\
\hline & 20 & $45.83(3.88)$ & $43.33(4.08)$ & $33.33(0.00)$ & $33.33(13.61)$ & $25.00(8.33)$ \\
\hline & 40 & $30.21(3.13)$ & $20.00(6.24)$ & $25.00(8.33)$ & $33.33(0.00)$ & $16.67(0.00)$ \\
\hline & 60 & 29.17 (4.17) & $20.00(6.24)$ & 8.33 (8.33) & 4.17 (4.17) & $16.67(16.67)$ \\
\hline \multirow[t]{5}{*}{ SB-4 } & 0 & $97.06(1.59)$ & $100.00(0.00)$ & $100.00(0.00)$ & $80.00(20.00)$ & $66.67(9.62)$ \\
\hline & 10 & 86.27 (4.10) & $86.67(3.33)$ & $91.67(8.33)$ & $80.00(6.24)$ & $61.11(5.56)$ \\
\hline & 20 & $72.55(4.27)$ & 73.33 (4.08) & $66.67(0.00)$ & $56.67(13.54)$ & $61.11(20.03)$ \\
\hline & 40 & $49.02(5.25)$ & $53.33(6.24)$ & $58.33(8.33)$ & $46.67(9.72)$ & $44.44(14.70)$ \\
\hline & 60 & $27.45(3.48)$ & $33.33(9.13)$ & $25.00(8.33)$ & $36.67(8.16)$ & $50.00(9.62)$ \\
\hline \multirow[t]{5}{*}{ SB-7 } & 0 & $92.22(2.22)$ & $88.89(5.56)$ & $83.33(0 / 00)$ & 88.89 (11.11) & $33.33(16.67)$ \\
\hline & 10 & $68.89(4.26)$ & $55.56(9.30)$ & $100.00(0.00)$ & $61.11(24.22)$ & $25.00(25.00)$ \\
\hline & 20 & $53.33(4.05)$ & $55.56(11.11)$ & $50.00(16.67)$ & $44.44(22.22)$ & 8.33 (8.33) \\
\hline & 40 & $31.11(4.56)$ & $27.78(10.24)$ & $16.67(0.00)$ & $27.78(14.70)$ & 8.33 (8.33) \\
\hline & 60 & $20.00(4.66)$ & $22.22(7.03)$ & 8.33 (8.33) & $5.56(5.56)$ & $50.00(16.67)$ \\
\hline \multirow[t]{5}{*}{ SB-8 } & 0 & $98.96(1.04)$ & 93.33 (4.08) & $94.44(5.56)$ & $88.89(5.56)$ & $55.56(14.70)$ \\
\hline & 5 & $96.88(1.68)$ & $93.33(4.08)$ & $100.00(0.00)$ & $100.00(0.00)$ & $22.22(11.11)$ \\
\hline & 10 & $95.83(1.86)$ & $86.67(9.72)$ & $100.00(0.00)$ & $88.89(5.56)$ & 38.89 (11.11) \\
\hline & 20 & 77.08 (3.99) & $63.33(9.72)$ & $66.67(9.62)$ & $66.67(9.62)$ & $50.00(25.46)$ \\
\hline & 40 & $20.83(2.85)$ & $30.00(6.24)$ & $16.67(9.62)$ & $16.67(9.62)$ & $33.33(25.46)$ \\
\hline
\end{tabular}

Note: Delay to larger-reinforcer is in seconds. SEM is standard error of the mean.

John $\mathrm{H}$.

Hagen 